\title{
tecnología de la gunita
}

LUIS MARTINEZ DIAZ, Dr. Ingeniero de Caminos, Canales y Puertos

\section{índice}

\begin{tabular}{|c|c|c|c|c|c|}
\hline . & TECNOLOGIA DE LA GUNITA $\ldots \ldots \ldots \ldots \ldots$ & 44 & 2. & USOS DE LA GUNITA & 56 \\
\hline .1. & Generalidades. Normas $\ldots \ldots \ldots \ldots \ldots \ldots$ & 44 & 2.1 . & Generalidades & 56 \\
\hline 1.2. & 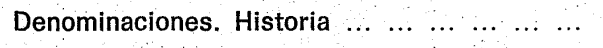 & 44 & 2.2 . & En estructuras nuevas & 56 \\
\hline 1.3. & Equipo de aplicación. Clases de gunita ...... & 45 & 2.3. & En túneles $\begin{array}{lllllllllllll} & \ldots & \ldots & \ldots & \ldots & \ldots & \ldots & \ldots & \ldots & \ldots & \ldots & \ldots\end{array}$ & 57 \\
\hline 1.4. & 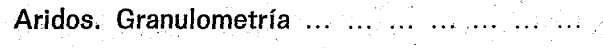 & 46 & 2.4 . & En recubrimientos $\ldots \ldots \ldots \ldots \ldots \ldots \ldots$ & 59 \\
\hline 1.5 . & Cemento. Dosificaciones $\ldots \ldots \ldots \ldots \ldots$ & 47 & 2.5. & En revestimientos refractarios $\ldots \ldots \ldots \ldots \ldots$ & 59 \\
\hline 1.6. & Agua. Relación agua/cemento $\ldots \ldots \ldots \ldots \ldots$ & $\begin{array}{l}49 \\
50\end{array}$ & 2.6 & En reparación de canales ... ....... & 60 \\
\hline 1.8. & 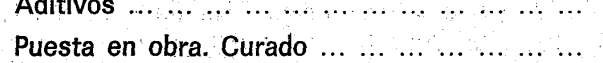 & 50 & 2.7. & En reparación de estructuras ....... & 60 \\
\hline 1.9. & 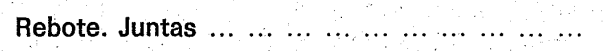 & 51 & 2.8 & Medición de gunitados ... & 60 \\
\hline 1.10. & Resistencia. Ensayos & 54 & 2.9 . & Conclusiones ... & 61 \\
\hline
\end{tabular}

\section{normas de ejecución}

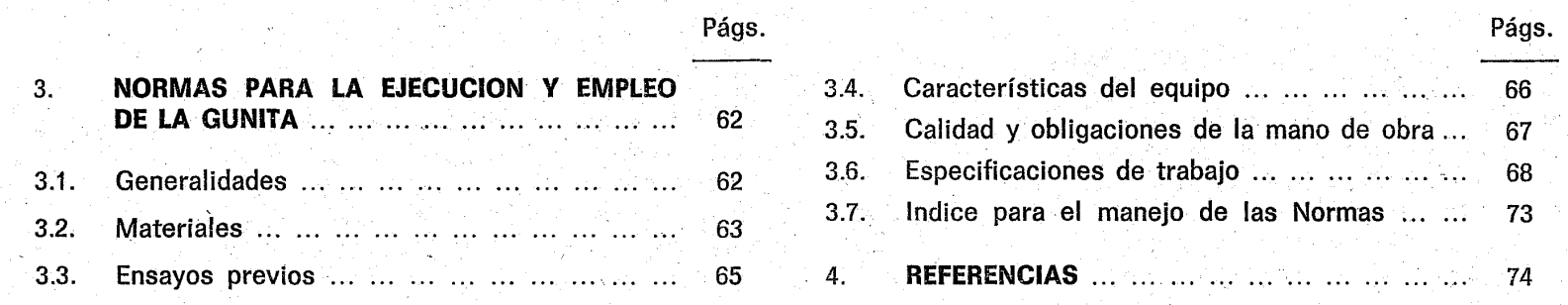




\begin{abstract}
sinopsis Se describen en este artículo las características, denominaciones, dosificación y usos, asi como las normas para una correcta ejecución y puesta en obra de los morteros y hormigones transportados a través de manguera y proyectados neumáticamente a gran velocidad, sobre una superficie, a los que en España se denomina, genéricamente, con el 838-1 nombre de gunita.
\end{abstract}

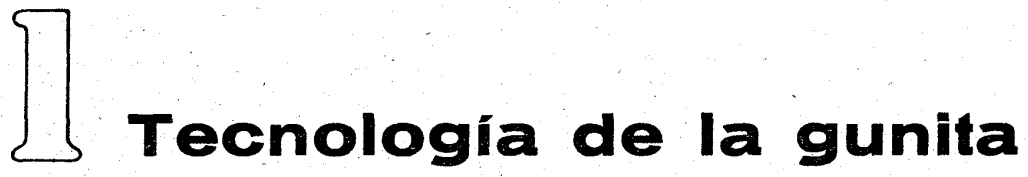

\subsection{GENERALIDADES. NORMAS}

El uso de morteros y hormigones transportados y puestos en obra mediante aire a presión - genéricamente denominados gunita en nuestro país - ha aumentado sin cesar en los últimos años. Las mejoras introducidas en el equipo de aplicación, el progresivo conocimiento de sus características y el empleo de personal cada vez mejor adiestrado - factor éste de la mayor importancia- explican, con la versatilidad del material, el auge de su empleo.

La aInstrucción para el proyecto y la ejecución de obras de hormigón en masa o armado", vigente desde septiembre de 1970, no contiene prescripciones de ninguna clase para la confección, puesta en obra y utilización de los morteros y hormigones proyectados.

En U.S.A. y en Europa, después de la segunda guerra mundial, estos materiales empezaron a usarse sistemáticamente para resolver determinados problemas constructivos y, en el primero de dichos países, existían ya, desde 1951, las normas del American Concrete Institute, denominadas "Recommended Practice for the Application of Mortar by Pneumatic Pressure (A.C.I., 805-51) n que, el año 1966, se actualizaron con el A.C.I. Standard, «Recommeded Practice for Shotcreting (A.C.I., 506-66) „; abreviadamente: R.P.S. 1966

Al comprobar el autor, durante su gestión como director de Gunita, S. A. la utilidad práctica de estas últimas normas (R.P.S. 1966), las tradujo al español; con permiso del American Concrete Institute, fueron publicadas en 1970 y constituyen el capítulo 3 de esta publicación.

Creemos de algún interés el exponer un resumen de nuestra experiencia e información sobre este tema, como consecuencia de las actividades citadas.

\subsection{DENOMINACIONES. HISTORIA}

En España se usó el nombre de GUNITA, derivado del de la primera máquina de colocación americana "cementgun", para designar este tipo de materiales. Por dicha razón lo emplearemos en estas notas, así como también el verbo bárbaro de gunitar, ambas palabras incorporadas ya a nuestro quehacer técnico.
En U.S.A., por la misma razón que en nuestro país, se llamó inicialmente agunite» al mortero proyectado; posteriormente, con mayor propiedad, «sprayed concrete 0 "pneumatically applied mortar" (P.A.M.) y últimamente "shotcrete"; nombre que engloba tanto el mortero como los hormigones colocados neumáticamente en obra, desarrollados últimamente.

En Alemania se llama a este material "spritzbeton" u hormigón proyectado; así como también "torKret», curioso nombre formado con las sílabas medias de las palabras latinas "tectorium", funda o revestimiento y "concretum", equivalente latino de hormigón.

En Francia se emplea la expresión: "béton proyectéen, y en Italia sigue Ilamándosele "gunite». En Suecia y Suiza, respectivamente, "sprutbetong" y uspritzmorter".

La idea de colocar en obra, mediante aire a presión, mezclas de arena y cemento, a las que se añadía el agua en la boquilla de salida, empezó a llevarse a la práctica, con éxito, a principios de siglo. Según Santarella, Carlo A. Keley fue uno de los iniciadores de esta técnica, en el año 1907. En América del Norte, por esos años, Ilamaron la atención los revestimientos de galerías, llevados a cabo por el ingeniero de minas $\mathrm{Cr}$. Rice, utilizando las primitivas máquinas "cement-gun" que se emplearon también para la protección de pilares metálicos contra el fuego y revestimiento interior de depósitos y tuberías de gran diámetro.

Se citan, como notables realizaciones de este primer período, unas lanchas de desembarco construidas en 1919, que se encontraban en buen estado después de 25 años de contacto con el agua salada, y unos muros en el norte de Michigán en los que, al ser reparados en 1930, la gunita se encontraba en perfectas condiciones a pesar de haber soportado durante 21 años la baja temperatura ambiente.

Hasta después de la segunda guerra mundial el uso de la gunita estuvo restringido por la limitación, hasta áridos de $8 \mathrm{~mm}$ de $\varnothing$ máximo, del primitivo equipo de aplicación. En los últimos 25 años, las mejoras introducidas en los aparatos primitivos de doble cámara y la puesta en el mercado de otros equipos de alimentación continua, de distinta concepción, permitieron colocar en obra, por este 
procedimiento, mezclas con áricos hasta de $30 \mathrm{~mm}$ de $\varnothing$; es decir, verdaderos hormigones. Desde entonces la tecnología y los usos de la gunita, con áridos en la práctica hasta de $25 \mathrm{~mm}$ de $\phi$, se han desarrollado considerablemente y son el objeto de estas notas.

\subsection{EQUIPO DE APLICACION. CLASES DE GUNITA}

La gunita es genéricamente, con las precisiones que se irán estableciendo, un mortero u hormigón de cemento -transportado por manguera y proyectado sobre una superficie neumáticamente- cuya evolución y mejora ha sido paralela a la del equipo de aplicación.

El año 1910, en la Exposición del Cemento del Mádison Square Garden de Nueva York, la Cement Gun Company exhibió la primera máquina para fabricación de gunita. Según T. R. Crom, esta empresa, que cambió su primitivo nombre por el de Allentown Pneumatic Gun Company, fue durante algún tiempo la única suministradora de esta clase de equipo, que sigue todavía fabricando. Pronto, en U.S.A. y en Europa, se fabricaron por otras compañías aparatos análogos, del tipo de doble cámara, que singularmente han seguido usándose hasta la fecha con ligeras modificaciones y mejoras, que no afectan a su concepción básica de estar constituidos por dos depósitos: el superior para carga de los materiales y el inferior para su paso, mediante presión neumática, al dispositivo de colocación en obra. La figura 1 es una sección transversal de un aparato moderno de este tipo, que no precisa mayores aclaraciones.

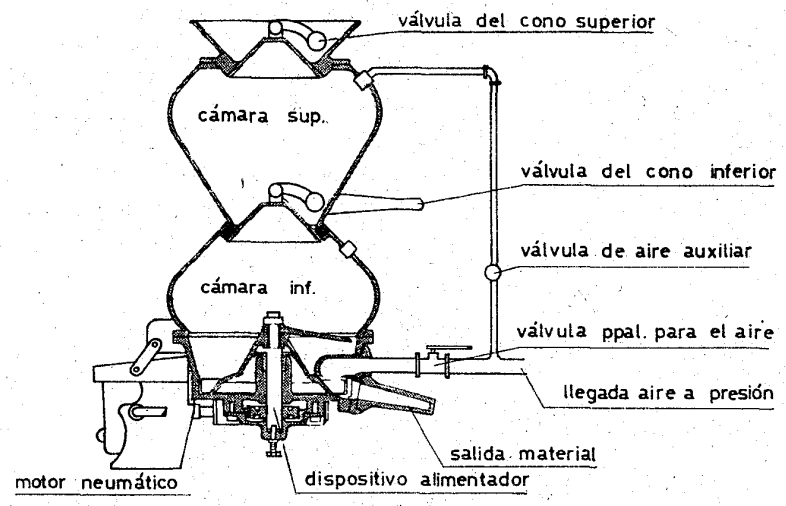

Fig. 1. Gunitadora de doble cámara.

La ventaja de proyectar mezclas secas con áridos de diámetro superior a $7 \mathrm{~mm}$, se hizo evidente: por precisar menores dosificaciones de cemento por $\mathrm{m}^{3}$, reducir la excesiva retracción de fraguado y poder utilizarse como material estructural para hormigón armado. Se han creado, como consecuencia, en los últimos 25 años, nuevos tipos de máquinas de mayor tamaño y rendimiento, que permiten gunitar mezclas secas con áridos hasta de $30 \mathrm{~mm}$ de $\varnothing$ (de $\varnothing 25 \mathrm{~mm}$ en operación normal).

Nuevos tipos de gunitadoras, de mayor tamaño y algunas de alimentación continua y concepción mecánica distinta,
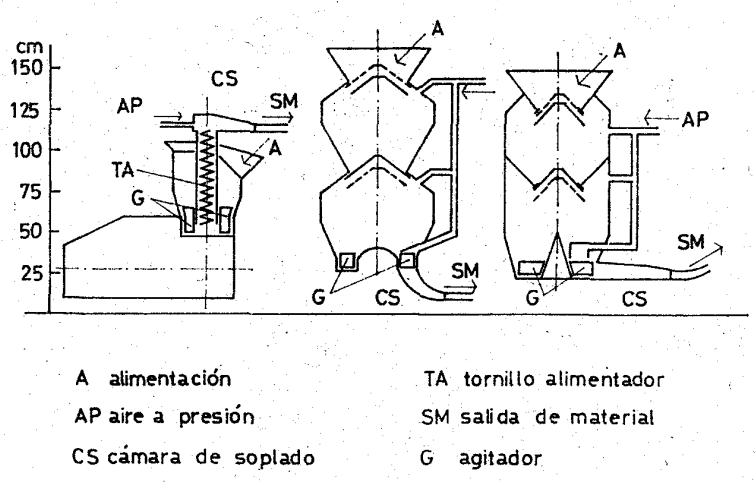

Fig. 2. Tipos de gunitadoras.

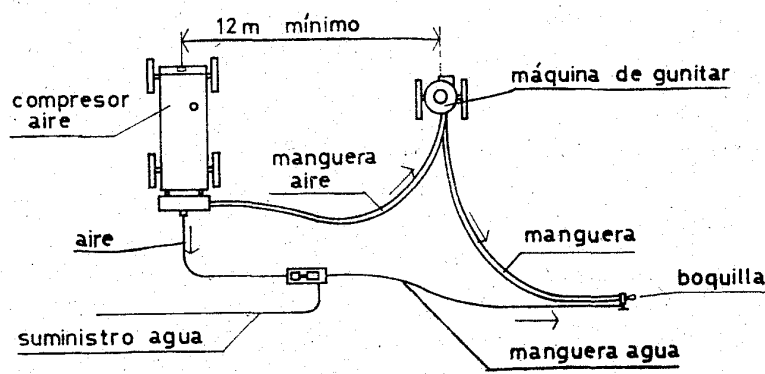

Fig. 3. Equipo de gunitado.

como la ALIVA, se usan actualmente y se muestran comparativa y esquemáticamente en la figura 2.

Cualquiera de estas máquinas precisa, para la fabricación de gunita por vía seca, que después definiremos, una instalación para el suministro de aire y agua a presión, que completa el equipo de gunitado, que se representa esquemáticamente en la figura 3 . Existen también en el mercado instalaciones móviles compactas montadas sobre camiones; o de otros tipos para aplicaciones especiales.

Este equipo se emplea para la fabricación de gunita por vía seca, llamada así cuando la mezcla en seco áridoscemento se une al agua de fraguado en la boquilla de salida al exterior, por intermedio de un anillo perforado. Este sistema fue el que primero se utilizó y el que corrientemente se emplea y viene descrito, sin que precise mayores aclaraciones, en el apartado 102 de las traducidas R.P.S. (Recommended Practice for Shotcreting).

A partir de 1955 se han desarrollado, en U.S.A. y otros paises, equipos que permiten la colocación neumática de hormigones, previamente formados por la mezcla de sus tres componentes, cemento-áridos-agua. Estos hormigones se transportan hasta la boquilla de salida mediante bombeo mecánico o presión neumática. Este sistema de fabricación y colocación, denominado gunita por vía húmeda, es de menor rendimiento debido al fuerte rozamiento de los componentes mojados del hormigón con la pared interior de la manguera. El sistema de vía húmeda se describe en el apartado 102 de las R.P.S. y se está desarrollando para el uso de la gunita estructural.

En la figura 4 puede verse la sección croquizada de una gunitadora para el sistema de vía húmeda con impulsión de transporte neumática. Existen también equipos móviles y compactos de distinta concepción del representado. 


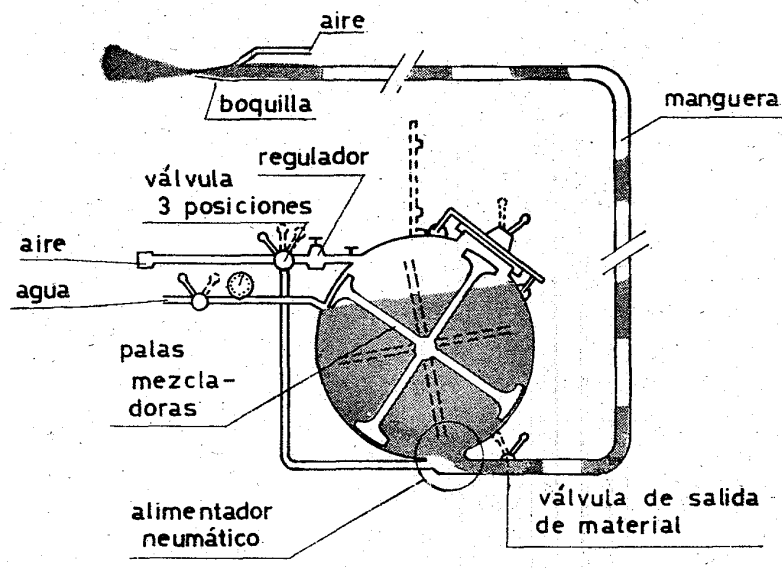

Fig. 4. Gunitadora viá húmeda.

Copiamos de la traducción de las R.P.S. la comparación entre ambas clases de gunita:

\section{TABLA I.}

\begin{tabular}{|c|c|}
\hline Miezcla en seco & Mezcla por vía húmeda \\
\hline $\begin{array}{l}\text { 1. Se tiene en la boquilla } \\
\text { el control del agua y } \\
\text { la consistencia de la } \\
\text { mezcla. } \\
\text { 2. Más adecuado para el } \\
\text { manejo de las mezclas } \\
\text { que contengan agre- } \\
\text { gados porosos y lige- } \\
\text { ros. } \\
\text { 3. Permite una mayor } \\
\text { longitud de la man- } \\
\text { guera de entrega. }\end{array}$ & $\begin{array}{l}\text { 1. La adición del agua se } \\
\text { controla en el equipo } \\
\text { de transporte y puede } \\
\text { medirse exactamente. } \\
\text { 2. Mayor seguridad de } \\
\text { que el agua se mezcla } \\
\text { totalmente con los } \\
\text { otros componentes. } \\
\text { Menores pérdidas por } \\
\text { rebote. } \\
\text { 3. Se produce menos pol- } \\
\text { vo durante la opera- } \\
\text { ción. }\end{array}$ \\
\hline
\end{tabular}

Mediante cualquiera de los dos procesos anteriores se pueden colocar en obra, por capas de espesor $5-10 \mathrm{~cm}$, morteros y hormigones de características físicas y mecánicas análogas a los obtenidos por procedimientos convencionales, y que vamos, por lo tanto, a examinar utilizando la terminología ordinaria.

Empleando áridos ligeros, porosos o refractarios, se pueden conseguir una variedad de tipos de gunita, a los que la diferente densidad confiere propiedades aislantes, refractarias o las propias para obtener estructuras ligeras o pesadas. Barnard y Tobin clasifican estas variedades posibles de gunita en los cuatro tipos siguientes:

TABLA II

1. Gunita de relleno o aislante $\left(650 / 1.450 \mathrm{~kg} / \mathrm{m}^{3}\right)$, áridos porosos.

2. Gunita estructural ligera $\left(1.450 / 1.920 \mathrm{~kg} / \mathrm{m}^{3}\right)$, áridos, pizarras o margas.

3. Gunita normal $\left(1.920 / 2.560 \mathrm{~kg} / \mathrm{m}^{3}\right)$, áridos calizos o silíceos.

4. Gunita pesada $\left(2.560 / 3.300 \mathrm{~kg} / \mathrm{m}^{3}\right)$, áridos especiales pesados. Estas calidades se representan esquemáticamente en la figura 5 .

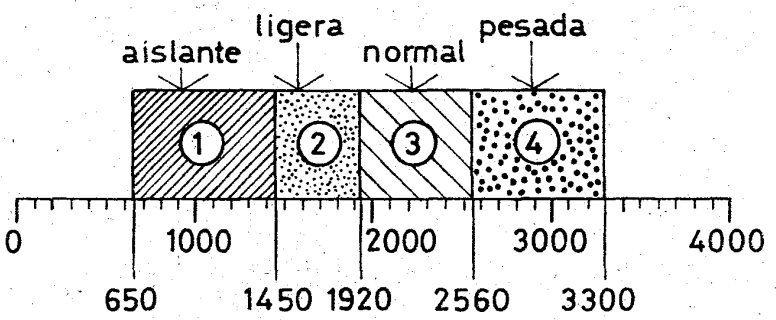

Fig. 5. Tipos de gunita.

\subsection{ARIDOS. GRANULOMETRIA}

Dejando aparte el empleo de áridos especiales usados para obtener tipos de gunita también especiales, a los que hemos aludido en la precedente tabla II, la calidad de las arenas y gravas necesarias para tener una buena gunita se rige por las misma reglas válidas para los hormigones y morteros ordinarios. En cuanto a su granulometría, como consecuencia del desarrollo en dos fases de la gunita que hemos expuesto en el apartado 2, esa misma separación se sigue manteniendo en la práctica, y en las recomendaciones de las normas R.P.S. que establecen los dos tipos de prescripciones de las tablas III y IV siguientes. En la primera como aproximación deseable y en la segunda indicando tres tipos de granulometrías adecuadas según el uso del material.

TABLA III. Gunita con áridos finos ( $\varnothing$ hasta $7 / 8 \mathrm{~mm}$ ).

\begin{tabular}{c|c|c}
\hline $\begin{array}{c}\text { Tamices Standard } \\
\text { U.S.A. }\end{array}$ & Mallas (mm) & $\%$ en peso que pasa \\
\hline $3 / 8^{\prime \prime}$ & 9,52 & 100 \\
Núm. 4 & 4,76 & $95-100$ \\
Núm. 8 & 2,38 & $80-100$ \\
Núm. 16 & 1,19 & $50-85$ \\
Núm. 30 & 0,595 & $25-60$ \\
Núm. 50 & 0,297 & $10-30$ \\
Núm. 100 & 0,149 & $2-10$ \\
\hline
\end{tabular}

TABLA IV. Gunita con áridos gruesos ( $\varnothing$ hasta $25 \mathrm{~mm}$ ).

\begin{tabular}{|c|c|c|c|c|}
\hline \multirow{2}{*}{$\begin{array}{c}\text { Tamices } \\
\text { U.S.A. }\end{array}$} & \multirow{2}{*}{$\frac{\text { cuadrada }}{\text { (mm) }}$} & \multicolumn{3}{|c|}{$\%$ en peso que pasa } \\
\hline & & $\begin{array}{c}\text { Del núm. } 8 \\
\text { al } 3 / 8 "\end{array}$ & $\begin{array}{c}\text { Del núm. } \\
\text { al } 1 / 2 "\end{array}$ & $\begin{array}{l}\text { Del núm. } 4 \\
\text { al } 1 / 2,\end{array}$ \\
\hline $1 "$ & 25,4 & - & - & 100 \\
\hline $3 / 4 "$ & 19,05 & - & 100 & $90-100$ \\
\hline $1 / 2^{\prime \prime}$ & 12,70 & 100 & $90-100$ & $\longrightarrow$ \\
\hline $3 / 8^{\prime \prime}$ & 9,52 & $85-100$ & $40-70$ & $20-25$ \\
\hline $\mathrm{N}:{ }^{\circ} 4$ & 4,76 & $10-30$ & $0-15$ & $0-10$ \\
\hline N. 8 & 2,38 & $0-10$ & $0-5$ & $0-5$ \\
\hline N. 16 & 1,19 & $0-5$ & - & - \\
\hline
\end{tabular}

Debiendo tenerse en cuenta que los áridos finos precisan dosificaciones más ricas de cemento y producen mayores retracciones de fraguado que los gruesos; los que, en cambio, dan lugar a mayores pérdidas por rebote. 
TABLA V. Comparación. Granulometrías.

\begin{tabular}{|c|c|c|c|c|c|c|c|c|c|c|c|}
\hline & $\therefore$ & $\begin{array}{c}\text { Tamices } \\
(\mathrm{mm})\end{array}$ & 0,2 & 1 & 3 & 7 & 10 & 15 & 20 & 25 & 30 \\
\hline & & $\begin{array}{c}\text { Tamices } \\
\text { (pulgadas) }\end{array}$ & $1 / 64$ & $3 / 64$ & $1 / 8$ & 9/32 & $25 / 64$ & $19 / 32$ & $25 / 32$ & $63 / 64$ & $13 / 16$ \\
\hline & & Convencional & $2-15$ & $20-40$ & $50-70$ & 100 & & & & & \\
\hline & $\stackrel{n}{\stackrel{2}{c}}$ & A.M.B. & $2-15$ & $20-40$ & $56-72$ & 100 & & & & & \\
\hline & : & Drögsler & $8-22$ & $30-50$ & $64-80$ & 100 & & & & & \\
\hline & $\frac{\bar{z}}{\frac{\pi}{\alpha}}$ & Línea B & 15 & 40 & 72 & 100 & & & & & \\
\hline$\infty$ & & A.S.T.M. & $5-17$ & $41-75$ & 78-92 & $97-100$ & 100 & & & & \\
\hline $\bar{z}$ & & Convencional & $2-15$ & $20-40$ & $50-75$ & $90-95$ & 100 & & & & \\
\hline $\overrightarrow{0}$ & : & Convencional & $5-20$ & $20-40$ & $30-65$ & $50-80$ & - & 100 & & & \\
\hline & 莺 & Convencional & $5-20$ & $20-40$ & $30-65$ & $50-80$ & - & $80-95$ & 100 & & \\
\hline & : & Convencional & $5-20$ & $20-40$ & $30-50$ & $50-70$ & - & $70-90$ & - & 100 & \\
\hline & 흔 & Drögsler, promedio & 10 & 26 & 46 & 64 & - & 87 & - & - & 100 \\
\hline & & Línea E & 9 & 24 & 43 & 60 & - & 82 & - & - & 100 \\
\hline
\end{tabular}

Los trabajos y experiencias europeos (Linder, Drögsler, Rothfuchs) conducen a dos tipos análogos de granulometrías que se representan, con escala logarítmica para las aberturas de tamices en la figura 6 , tomada de un trabajo de Drögsler, y en la que las líneas B y $E$ representan las granulometrías ideales para gunitas con áridos máximos de 7 y $25 \mathrm{~mm}$, respectivamente.

Las superficies rayadas a uno y otro lado de estas dos líneas comprenden las áreas de variación tolerables en la práctica y fueron trazadas mediante puntos obtenidos de las medias $\frac{A+B}{2}$ y $\frac{D+E}{2}$; siendo $A$ y $D$ otras dos líneas granulométricas extremas, también experimentadas.

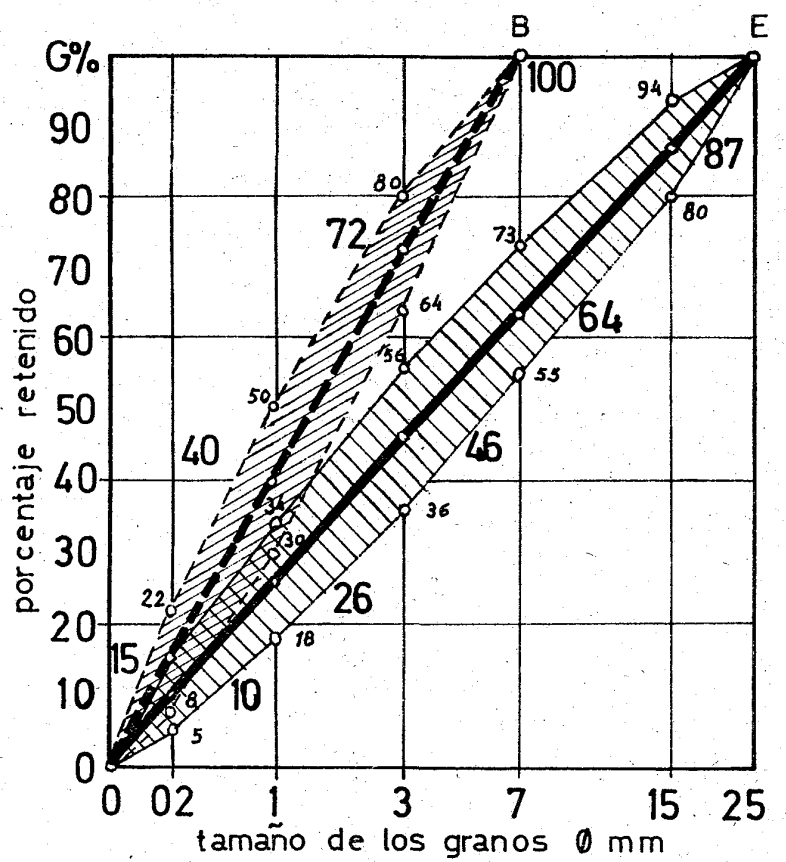

Fig. 6. Granulometrías tipo.
Resulta interesante la comparación de la tabla $V$ entre las granulometrías correspondientes a las líneas B y E de la figura 6, las prescritas por las normas alemanas A.M.B. (Anweisung für Mörtel und Beton), las A.S.T.M. (American Society for Testing Materials) americanas y las convencionalmente usadas en este país para gunitas de áridos finos y gruesos. Transcribimos, simplificando, el cuadro de G. Kobler.

Como puede verse, no existe una norma rígida para obtener la granulometría ideal; únicamente unos límites indicativos entre los que debe moverse el proyectista de un gunitado, para cada aplicación concreta y teniendo en cuenta los materiales disponibles. La tabla precedente muestra que pueden admitirse los áridos muy finos, pero debe desecharse el polvo por perjudicial: En general, los módulos de finura de 2,5 y 3,3 para cada tipo de gunita, con variaciones comprendidas entre $\pm 0,2$, son aceptables.

En el caso de gunitas por vía seca es preciso que los áridos, para el buen funcionamiento del equipo de colo. cación, tengan un cierto grado de humedad que oscila del 4 al $8 \%$. En general, la influencia de la relación agua/ cemento, la consistencia de la mezcla y la granulometría, de los que después trataremos, tienen más importancia, para obtener buenos rendimientos operativos, que pequeñas variaciones en la granulometría de los áridos.

\subsection{CEMENTO. DOSIFICACIONES}

En cuanto a calidad pueden emplearse para la gunita los cementos de tipo: P-250, P-350 y P-450, definidos en nuestro Pliego de Condiciones; con preferencia los dos últimos, de mejor calidad. Se pueden utilizar también cementos aluminosos, cuando se trate de recubrimientos refractarios, cuidando su gran calor de fraguado, y pueden asimismo usarse las puzolanas. Si se emplean aditivos se evitará su posible incompatibilidad con alguno de los aglomerantes indicados.

La dosificación normal oscila entre 300 y $375 \mathrm{~kg} / \mathrm{m}^{3}$; aunque puede ser necesario elevarla hasta $500 \mathrm{~kg} / \mathrm{m}^{3}$ o más como consecuencia de los ensayos iniciales, que deben 
realizarse siempre en obras importantes partiendo de los resultados de la experiencia en casos análogos.

La dosificación, en volumen, es, en obra, la más cómoda. Cuando se emplea hay que tener en cuenta la variación de volumen que experimenta la arena, debida a la humedad media del $6 \%$, que es necesaria para el buen funcionamiento del equipo de colocación. La granulometría del árido puede también hacer que varie el peso por volumen del mismo, cuando se emplean arenas a granel tomadas de montones.

En la tabla VI figuran, en el sistema métrico, los resultados de distintas dosificaciones en volumen, obtenidos por Barnard para hormigones de tipo ligero, que precisan mayor cantidad de cemento. Se trata de proporciones iniciales que difieren de las mezclas ya colocadas en obra.

TABLA VI. Dosificaciones gunita ligera.

\begin{tabular}{c|c|c}
\hline $\begin{array}{c}\text { Relación, en volumen, } \\
\text { cemento/áridos }\end{array}$ & $\begin{array}{c}\text { Cemento } \\
\left(\mathrm{kg} / \mathrm{m}^{3}\right)\end{array}$ & $\begin{array}{c}\text { Resistencia } \\
\mathbf{R}_{28}\left(\mathrm{kp} / \mathrm{cm}^{2}\right)\end{array}$ \\
\hline $1: 3,0$ & 550 & $335-420$ \\
$1: 3,5$ & 500 & $280-350$ \\
$1: 4,0$ & 450 & $245-295$ \\
$1: 4,5$ & 410 & $210-245$ \\
$1: 5,0$ & 385 & $175-210$ \\
\hline
\end{tabular}

Para evitar las complicaciones anteriores la proporción arena/cemento se suele establecer en peso de los materiales. De un modo aproximado a una proporción de $1 / 4,5$ en volumen, corresponde la de $1 / 4,0$ en peso. Es fácil pasar de una o otra forma de operar cuando la dosificación se prescriba de modo diferente al de operación en el campo.

La gunita colocada en obra es más rica en cemento que la mezcla inicial como consecuencia del rebote de las partículas gruesas del árido; por lo que este enriqueclmiento en usos normales es función de la granulometría empleada. Studebaker ha estudiado este fenómeno de enriquecimiento clasificando en tres grupos los tamaños del árido y empleando en todos los ensayos la relación $a / c$ límite para colocación sin desprendimiento. Los resultados expresados en peso son los de tabla vil.

TABLA VII. Enriquecimiento por colocación.

\begin{tabular}{c|c|c|c|c}
\hline \multicolumn{4}{c|}{ PROPORCIONES ARIDOS/CEMENTO, EN PESO } \\
\hline \multirow{2}{*}{ Iniciales } & \multicolumn{3}{|c|}{ En obra para áridos } & \multirow{2}{*}{ Promedio } \\
\cline { 2 - 4 } & Finos & Medios & Gruesos & \\
\hline $1 / 3,0$ & $1 / 2,10$ & $1 / 2,00$ & $1 / 2,1$ & $1 / 2,0$ \\
$1 / 3,5$ & $1 / 2,75$ & $1 / 2,80$ & $1 / 2,8$ & $1 / 2,8$ \\
\hline $1 / 4,0$ & $1 / 3,10$ & $1 / 3,25$ & $1 / 2,9$ & $1 / 3,1$ \\
\hline $1 / 4,5$ & $1 / 3,35$ & $1 / 3,60$ & $1 / 3,6$ & $1 / 3,5$ \\
$1 / 5,0$ & $1 / 3,50$ & $1 / 3,80$ & $1 / 3,6$ & $1 / 3,6$ \\
$1 / 6,0$ & $1 / 3,90$ & $1 / 4,10$ & $1 / 4,3$ & $1 / 4,1$ \\
\hline
\end{tabular}

Se observa en la tabla que, para la proporción inicial más común de 1/4,0 con agregados de tamaño medio, la gunita, puesta en obra, llega a la dosificación $1 / 3,25$; valores que es útil retener al realizar los ensayos iniciales; en los que, de acuerdo con la tabla $\mathrm{VI}$, pueden esperarse en este caso resistencias del orden de 250 a $330 \mathrm{kp} / \mathrm{cm}^{2}$.

Como la teoría clásica del fraguado de los hormigones es válida para la gunita, el problema de su dosificación, en cemento, puede estudiarse en función de la superficie total de los granos del árido. Para las granulometrías más finas serán necesarias mayores cantidades de cemento por $\mathrm{m}^{3}$. Drögsler ha hecho experiencias en esta dirección, cuyos resultados se representan en la figura 7 , con datos correspondientes a gravas y arenas de densidad 2,65 para las que se ha determinado la superficie total de los granos de un $\mathrm{kg}$ de material. Se ve que para áridos de $\varnothing 10 \mathrm{~mm}$ la superficie es de $0,226 \mathrm{~m}^{2} / \mathrm{kg}$ mientras que para $\varnothing 1 \mathrm{~mm}$ es 10 veces mayor y 100 veces, o sea, $22,6 \mathrm{~m}^{2} / \mathrm{kg}$ para los áridos de $\varnothing 0,1 \mathrm{~mm}$.

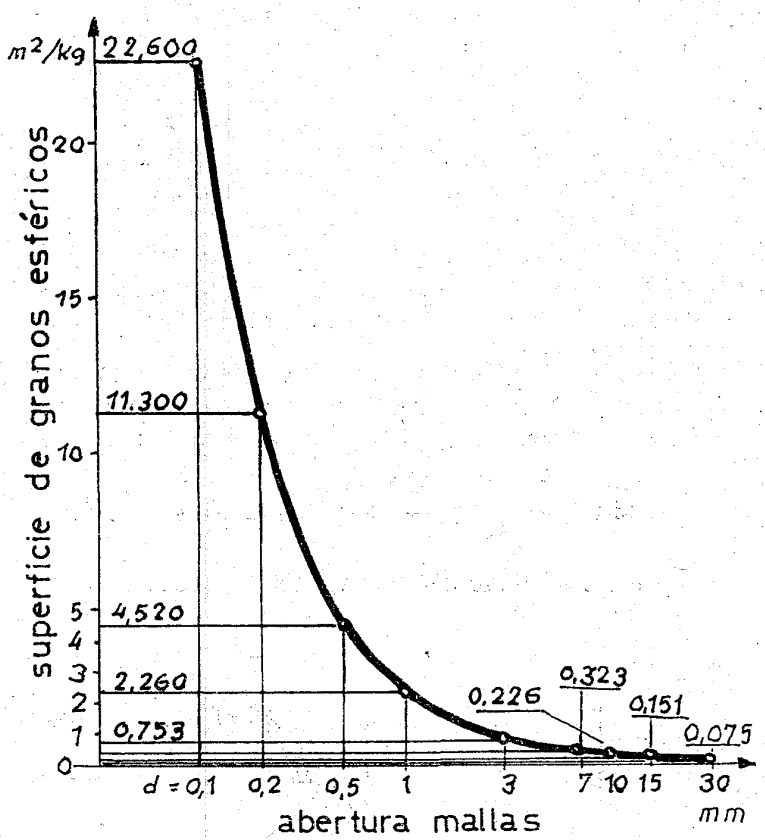

Fig. 7. Curvas superficie-tamaño de los granos (Drögsler).

Estudiando la variación de la superficie del árido asimilando su forma a un cuerpo geométrico, así como la influencia clasificadora de las cribas de mallas rectangulares o de agujeros circulares, se llega a los factores de equivalencia de la tabla VIII.

TABLA VIII. Proporciones entre superficies de áridos.

\begin{tabular}{l|c|c}
\hline \multirow{2}{*}{ Forma asimilable a: } & \multicolumn{2}{|c}{ TIPO DE CRIBA } \\
\cline { 2 - 3 } & Agujero 0 & Malla II \\
\hline Esferas & 1,0 & 1,0 \\
Hexaedros & 1,414 & 1,0 \\
Octaedros & 1,73 & 1,22 \\
Tetraedros & 2,84 & 2,36 \\
\hline
\end{tabular}


De esta tabla se deduce que los granos asimilables a tetraedros totalizan mayor superficie y son, por lo tanto, los menos convenientes. Análogamente el empleo de cribas con agujeros debe desecharse, puesto que proporciona granos de esta forma en mayor proporción $(2,84$, versus, 2,36$)$; en general al emplear cribas de agujeros se obtienen áridos más finos, que precisan mayor cantidad de cemento por $\mathrm{m}^{3}$ de gunita. Sobre este tema se volverá en el apartado siguiente.

\subsection{AGUA. RELACION AGUA/CEMENTO}

La calidad del agua y la influencia de su cantidad y su relación en peso con la del cemento que se emplee en la mezcla (relación $a / c$ ), se rige en el caso de la gunita por las mismas leyes establecidas para los hormigones. Sin embargo, como durante su puesta en obra la gunita fresca no debe desprenderse por su propio peso, y debe quedar adherida a la base, la consistencia o docilidad de la gunita se mueve entre límites más próximos que la de los hormigones. $Y$ el estudio del trinomio -agua/cemento/granulometría - tiene la especial importancia que se indicó en el apartado precedente. La figura 8 refleja los resultados de las experiencias de Brzesky, que empleando tres clases de cemento y granos máximos en los áridos de $12 \mathrm{~mm}$ a $30 \mathrm{~mm}$ experimentó con hormigones ordinarios y los tres valores $(0,55 ; 0,61 ; 0.68)$ de la relación a/c, que corresponden a las curvas (1), (2) y (3) de la figura 8, obtuvo las variaciones de la cantidad de $\mathrm{kg} / \mathrm{m}^{3}$ de cemento necesarios para obtener hormigones de la misma consistencia.

Estas curvas demuestran el rápido aumento de la cantidad de cemento necesario para obtener hormigones de la misma consistencia, para tres valores de a/c mantenidos constantes. La aplicación de estos resultados a la gunita, hace evidente la conveniencia de emplear el máximo ta-

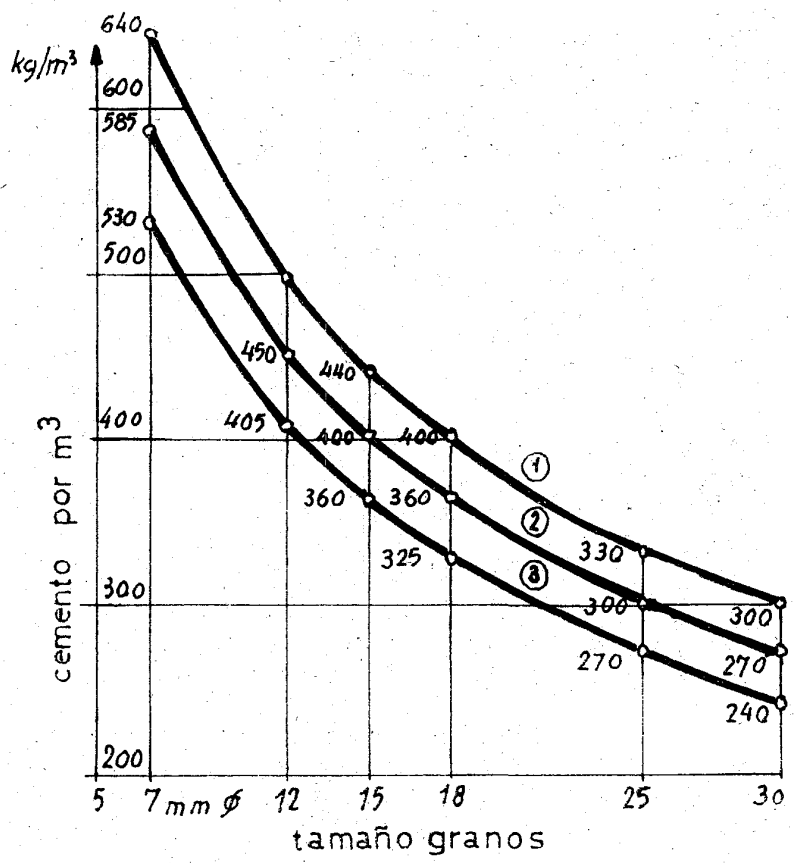

Fig. 8. Curva cemento-superficie granos-a/c (Brzesky). maño de árido que permitan las características de la obra y que condiciona también el sistema especial de colocación.

Consecuencia de lo anterịor es la variación, entre límites muy separados, de la relación a/c, que está fuertemente condicionada por las variaciones del módulo de finura del árido, y de la proporción en peso cemento/áridos, empleada en la mezcla. La tabla IX, resume los resultados de las experiencias de Studebaker realizadas variando: el tamaño del árido, y las proporciones en peso de las relaciones cemento/áridos y a/c. En estas experiencias las resistencias de prueba obtenidas fueron en promedio: $282 \mathrm{kp} / \mathrm{cm}^{2}$, estando la mayoría por debajo de $350 \mathrm{~kg} / \mathrm{cm}^{2}$ y obteniendo un máximo de $450 \mathrm{~kg} / \mathrm{cm}^{2}$ para 6 de las 299 muestras.

La condición uniforme impuesta a todos estos ensayos fue la de que se obtuviesen calidades de gunita de fácil puesta en obra, con porcentajes de rebote aceptables.

TABLA IX. Variaciones de las relaciones entre áridos, cemento y agua.

\begin{tabular}{|c|c|c|c|}
\hline Módulo de finura & $\begin{array}{c}\text { Cemento/árido } \\
\text { (en peso) }\end{array}$ & $\begin{array}{c}\text { Agua/cemento } \\
\text { (en peso) }\end{array}$ & $\begin{array}{l}\% \text { de agua de } \\
\text { los áridos } \\
\text { (en peso) }\end{array}$ \\
\hline \multirow{3}{*}{2,49} & $1 / 3,5$ & 0,54 & 20,0 \\
\hline & $1 / 4,0$ & 0,59 & 19,0 \\
\hline & $1 / 4,5$ & 0,65 & 19,5 \\
\hline \multirow[t]{2}{*}{ Aridos finos } & $1 / 5,0$ & 0,69 & 19,7 \\
\hline & $1 / 6,0$ & 0,80 & 20,5 \\
\hline \multirow{3}{*}{2,96} & $1 / 3,0$ & 0,37 & 18,5 \\
\hline & $1 / 3,5$ & 0,48 & 17,2 \\
\hline & $1 / 4,0$ & 0,55 & 17,1 \\
\hline \multirow[t]{3}{*}{ Aridos medios } & $1 / 4,5$ & 0,57 & 15,8 \\
\hline & $1 / 5,0$ & 0,62 & 16,3 \\
\hline & $1 / 6,0$ & 0,68 & 16,5 \\
\hline \multirow{2}{*}{3,26} & $1 / 3,0$ & 0,36 & 17,3 \\
\hline & $1 / 4,0$ & 0.44 & 15,0 \\
\hline \multirow[t]{2}{*}{ Aridos gruesos } & $1 / 5,0$ & 0,56 & 15,3 \\
\hline & $1 / 6,0$ & 0,65 & 15,0 \\
\hline
\end{tabular}

Es curioso observar, en la tabla IX, que la relación, en peso, entre el \% de contenido de agua sobre el de áridos, por $\mathrm{m}^{3}$, permanece relativamente constante alrededor del valor medio del $17 \%$, que puede aceptarse inicialmente para los ensayos previos en los casos de gunita de tipo normal y que equivale a unos 250 litros $/ \mathrm{m}^{3}$ en la boquilla de salida.

Drögsler, para gunitas con áridos del mismo módulo de finura, ha establecido la ecuación:

$$
\mathbf{R}_{28}=\mathbf{A} \cdot \mathbf{B}^{-\mathrm{a} / \mathrm{c}} \text {; }
$$

ecuación que relaciona las resistencias de rotura a los 28 días con la relación a/c, para hormigones o gunitas de la misma docilidad. A representa un paramento depen- 


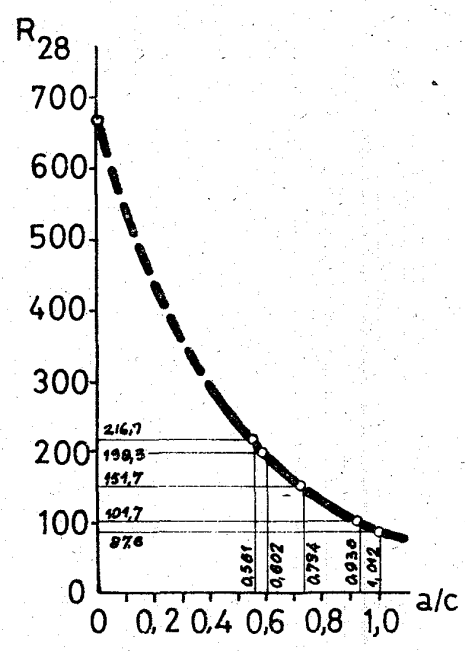

Fig. 9. Relación resistencia-a/c.

diente del cemento, y $\mathbf{B}$ otro que relaciona el agua con la consistencia. Para los valores $A=668$ y $B=7,5$, la curva de la ecuación anterior se da en la figura 9.

\subsection{ADITIVOS}

El cuarto componente de los hormigones, como suele llamarse a los aditivos, es de gran importancia en el caso de la gunita, dado su sistema de colocación y las necesidades consiguientes de: reducir al mínimo las pérdidas por rebote, obtener unas resistencias iniciales altas y una buena impermeabilidad en capas de poco espesor.

Las normas R.P.S. dedican su apartado 204 al tema, clasificando los aditivos, cuyo uso recomienda en la mayoría de los casos, en los grupos siguientes:

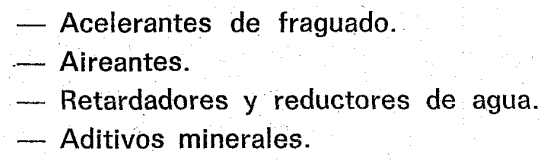

En la práctica es preferible el uso de un solo aditivo de prestigio comercial que suele contener, además de cal, siliconas, hidróxidos de metales pesados y a veces aceites minerales que actúan simultáneamente en todas las direcciones deseables de la forma siguiente: como acelerante, produciendo una concentración elevada de aluminato tricálcico que desplaza, acelerándolo, el equilibrio del proceso del fraguado; como impermeabilizante, dando lugar a la formación, en la estructura cristalina del cemento, de iones fuertemente hidrófugos, y como cohesionante, si contiene arcillas tixotrópicas que confieren esta propiedad, no al cemento, sino a la masa del material. En buenas condiciones de trabajo se reduce el rebote grandemente con la adición de productos de este tipo.

Al uso, también frecuente, de soluciones de cloruro de calcio al $20 \%$ añadidas al agua de mezclado, o de productos orgánicos, debe preferirse el de un aditivo comer- cial de prestigio que, en proporción aproximada del $3 \%$ del peso del cemento, garantiza, comprobándolo mediante ensayos previos, las facilidades de puesta en obra que se precisen, sin mengua sensible en la calidad final de la gunita, ni aumento de peligro de oxidación de las armaduras.

\subsection{PUESTA EN OBRA. CURADO}

El especial sistema de colocación de la gunita tiene sobre el del hormigón, para espesores hasta de unos $15 \mathrm{~cm}$, entre otras ventajas la de la economía en los encofrados, que puede llegar hasta su eliminación; aunque exige el empleo de una mano de obra muy bien adiestrada, para que puedan obtenerse resistencias finales del orden de las de los hormigones convencionales. J. Reading cita un caso en el que, empleando el mismo equipo mecánico de puesta en obra e idéntica composición del material, la resistencia bajó desde 420 a $105 \mathrm{kp} / \mathrm{cm}^{2}$, al sustituir por personal mal adiestrado, el muy bien entrenado que venía utilizándose.

Teniendo en mente esta observación diremos que, en el caso más general, la gunita se coloca en obra tal y como se indica a continuación: el operador mantiene la boquilla de salida a una distancia de la superficie a cubrir, que debe oscilar entre 0,75 y $1,25 \mathrm{~m}$, mientras gira ligeramente la boquilla alrededor de la posición normal a la superficie, y gradúa, en el caso de gunita por vía seca, el agua, aumentando ligeramente su proporción al comienzo y mantiene constante la presión de aire, de modo a obtener en la boquilla una velocidad de salida de alrededor de $100 \mathrm{~m} / \mathrm{s}$.

Las normas R.P.S. dan, para consumo y presión de aire en operación normal, los valores de la tabla $X$.

TABLA X. Presiones y consumos de aire.

\begin{tabular}{c|c|c|c}
\hline $\begin{array}{c}\text { m} / \text { hora } \\
\text { aire }\end{array}$ & $\begin{array}{c}\varnothing \text { manguera } \\
(\mathrm{cm})\end{array}$ & $\begin{array}{c}\varnothing \text { boquilia } \\
(\mathrm{cm})\end{array}$ & $\begin{array}{c}\text { Presión de } \\
\text { trabajo } \\
\left(\mathrm{kp} / \mathrm{cm}^{2}\right)\end{array}$ \\
\hline 425 & 2,5 & 1,9 & 2,8 \\
535 & 3,2 & 2,5 & 3,2 \\
620 & 3,8 & 3,2 & 3,9 \\
850 & 4,1 & 3,8 & 4,6 \\
1.020 & 4,4 & 4,1 & 5,3 \\
1.275 & 5,1 & 4,4 & 6,0 \\
\hline
\end{tabular}

La superficie que va a gunitarse se limpia muy bien antes de comenzar la operación; en ocasiones se emplea, para esta limpieza, aire o agua a presión y un chorro de arena, que pueden obtenerse con el mismo aparato de colocación.

Una vez iniciada la operación, el proceso de gunitado se regula en cierto modo por sí mismo. En efecto, al comenzar la proyección del material de la forma indicada, se forma sobre la superficie tratada una primera capa de arena muy fina y cemento, que va aumentando su espesor al incrustarse en la misma granos más gruesos del árido. 
El agua debe regularse en esta fase del proceso de manera que la primera capa presente una superficie brillante, pero no descuelgue. Cuando se llega a un espesor de $0,5 \mathrm{~cm}$ a $1,0 \mathrm{~cm}$, se comienza a proyectar la mezcla normal, cuyos granos, más gruesos en parte, penetran en la primera capa y quedan envueltos en ella; otros la atraviesan completamente, chocan con el fondo duro y caen al suelo, comenzando así a formarse el rebote. Mientras los áridos finos siguen llegando mezclados con cemento y aumentando hasta unos $2 \mathrm{~cm}$ el espesor de la capa adherida, que rechaza determinada parte del material, que permanece constante durante toda la operación y constituye propiamente el llamado rebote, el cual se estima en \% de la cantidad de material que sale por la boquilla. En esta fase final parte de los áridos gruesos envueltos con cemento chocan con otros de igual o parecido tamaño, ya fijos, a los que introducen en el espesor tota de la capa, mientras que otros son rechazados y al chocar con el cono de proyección caen al suelo en las proximidades de la zona de trabajo, incrementando así el rebote. El proceso descrito conduce a igualar la composición de las primeras capas con las siguientes, produciendo la notable semejanza estructural de la gunita en todo su espesor.

La influencia de las variables: velocidad-distancia-dirección en el proceso de colocación, es muy dispar y ha de apreciarse objetivamente durante el trabajo, que precisa, por lo tanto, una mano de obra muy calificada que sepa regular, optimizándolo en todo momento, el sistema de trabajo.

Cuando la gunita se destina a la formación de morteros $u$ hormigones armados, el proceso de puesta en obra se complica todavía más por la necesidad de que las arma-
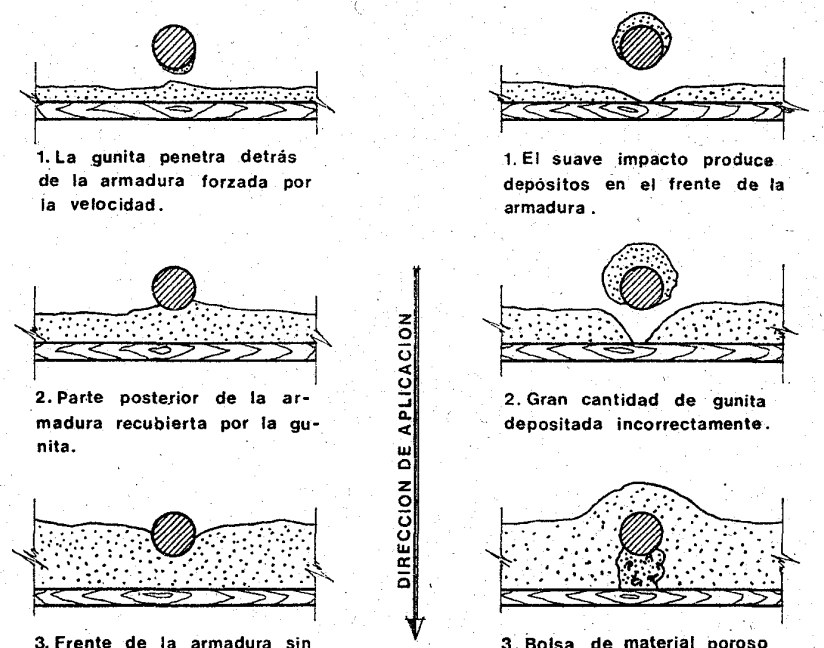

3. Frente de la armadura $\sin$ recubrir aun.

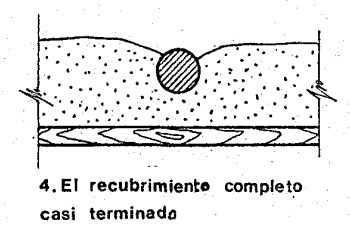

Fig. 10. Proceso de recubrimiento de las armaduras.

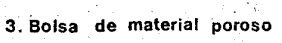
tras la armadura.

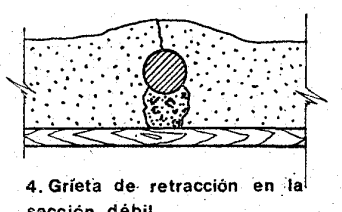
sección débil. duras queden perfectamente envueltas por la gunita y la de evitar que, en las zonas "en sombra" de las mismas, se formen perjudiciales bolsas de arena, con un contenido pobre de cemento. La figura 10 es muy aclaratoria a este respecto y procede de las R.P.S.

De lo expuesto anteriormente se llega a la conclusión de que no es prudente contar con los rendimientos del equipo de colocación, que se indican en los catálogos; sobre todo en la fase inicial de cada obra. Aun con las máquinas de mayor tamaño y empleando áridos hasta de $\varnothing 25$ milímetros, un rendimiento muy bueno en operación continua puede ser el de $3 \mathrm{~m}^{3} / \mathrm{hora}$, muy difícil de superar. Con áridos de $\varnothing 12$ y $15 \mathrm{~mm}$ y máquinas de tipo medio, que es el caso más frecuente, se pueden obtener rendimientos de 1,0 y $1,5 \mathrm{~m}^{3} /$ hora. En todos los casos, el rendimiento en obra suele oscilar entre $1 / 1,5$ a $1 / 3$ del teórico.

La gunita se coloca por capas sucesivas hasta llegar -al espesor deseado. El de cada capa oscila desde $3 \mathrm{a} 15 \mathrm{~cm}$, dependiendo de la posición de la capa y, sobre todo, del empleo de aditivos, que favorecen la adherencia. En casi todos los casos en los que se emplea la gunita, su espesor suele ser menor que en el de los que se utiliza el hormigón ordinario. De aquí que sean precisos mayores cuidados para la cura de la gunita, cuya superficie debe mantenerse húmeda mediante riegos durante los primeros 7 días. Asimismo, debe suspenderse el gunitado cuando las temperaturas se acerquen a $0^{\circ} \mathrm{C}$ y cubrir las superficies ya gunitadas mientras duran las temperaturas bajas. Si se emplean productos de curado superficial, sólo podrán extenderse sobre la última capa, y su rendimiento, debido a la rugosidad superficial de la gunita, es mucho más bajo que el ordinario.

\subsection{REBOTE. JUNTAS}

En el párrafo anterior se han indicado las causas que, durante el proceso de puesta en obra de la gunita, dan lugar a la formación del rebote o rechazo, formado por una parte de los materiales de la mezcla inicial que no se quedan adheridos a la superficie gunitada, caen al suelo y hay que retirar de la obra, sin que sea conveniente su utilización posterior. Constituye el rebote, que se estima en $\%$ del volumen inicial de la mezcla, una pérdida en la operación de gunitado que conviene reducir al mínimo.

El rebote varía, según las condiciones operativas, entre límites muy extensos (del 5 al $50 \%$ ) y se reduce en general con el empleo de aditivos. Está compuesto por granos relativamente secos, que tienen adherida una fina capa de cemento, que oscila de 30 a $80 \mathrm{~kg} / \mathrm{m}^{3}$, y con un bajo contenido de agua. Ambas circunstancias varían al mejorar las características de la gunita.

Desde el punto de vista de pérdida de materiales, el fenómeno del rebote no tiene importancia económica; pero la tiene, y mucha, por bajar el rendimiento del equipo de colocación, incidiendo de modo importante en costo de la gunita colocada.

Las normas R.P.S. consideran aceptables, en relación con el tipo de obra, rebotes entre los límites indicados en la tabla XI. 
TABLA XI. $\%$ de rebote admisible.

\begin{tabular}{l|r}
\hline \multicolumn{1}{c|}{ Tipo de superficie } & $\%$ de rebote \\
\hline Pisos o losas & 5 al 15 \\
Muros verticales o inclinados & 15 al 30 \\
Techos & 25 al 50 \\
\hline
\end{tabular}

El tema ha sido analizado por Linder con algún detalle dibujando, figura 11, las curvas que lo relacionan con el tamaño del árido. En la figura 12, también de la misma fuente, se muestra cómo varía el rebote con la relación a/c; de tal modo que para valores muy bajos de esta variable, al no haber suficiente agua ni para el fraguado

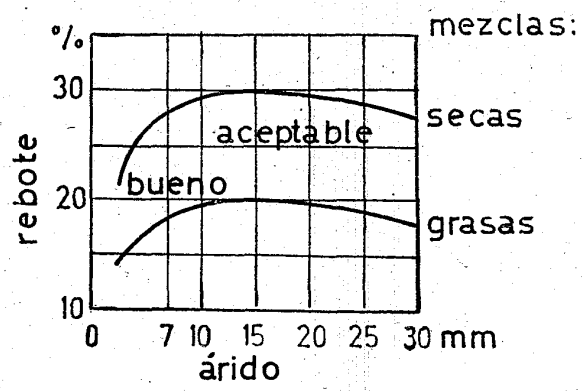

Fig. 11. Curva rebote- $\varnothing$ grano (Linder).

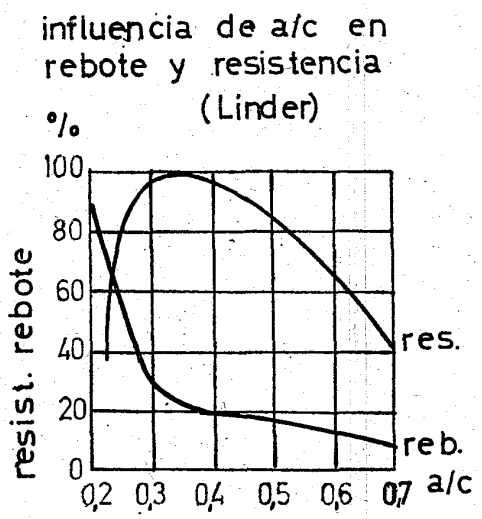

Fig. 12. Curva rebote-resistencia-a/c.

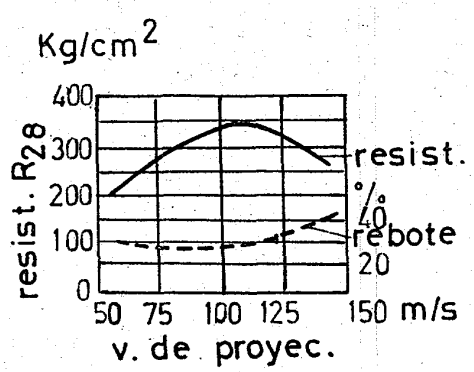

Fig. 13. Curva resistencia-velocidad de proyección (Linder).

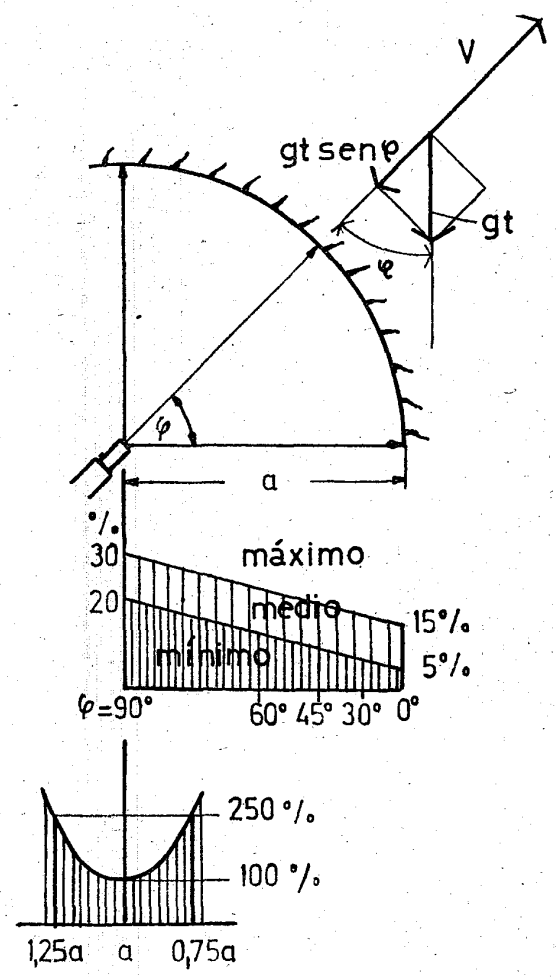
Fig. 14. Valor del rebote según la distancia y el ángulo de proyección

ni para la adherencia de la gunita, bajan ambas características que señalan unos valores óptimos de rebote $(15$ a $20 \%$ ) para una $a / c=0,35$ y máxima resistencia. En la figura 13 pueden verse las variaciones del rebote y de la calidad de la gunita, con la variable velocidad de proyección a la salida de la boquilla, en el intervalo de 50 a $150 \mathrm{~m} / \mathrm{s}$.

La variable más interesante por su influencia en el \% de rebote es, sin embargo, la distancia de proyección y la inclinación con la vertical de la superficie sobre la que se proyecta la gunita. Ambas se consideran en la figura 14 , variando entre 0,75 y $1,25 \mathrm{~m}$ y $0 / 90^{\circ}$, respectivamente. Se observa en la figura que los \% que se consideran aceptables, como promedio para los casos extremos, son 5 y $15 \%$ y 20 y $30 \%$.

El problema puede abordarse también analíticamente observando, en la misma figura 14, que si un grano sale con la velocidad ' $V^{\prime}$ en una trayectoria que forma un ángulo $\varphi$ con la vertical, la velocidad de llegada es:

$$
\mathbf{V}=\mathbf{V}^{\prime}-\mathbf{g} \cdot \mathbf{t} \cdot \operatorname{sen} \varphi ;
$$

en la que, siendo $t$ el tiempo que tarda en llegar y $\mathbf{g}$ la aceleración de la gravedad, el sustraendo tiene un valor relativo muy pequeño. La penetración $\mathbf{P}$ de un grano de $\varnothing$ d depende de su fuerza viva

$$
f=\frac{m \cdot V^{\prime 2}}{2} \quad ; \quad m=\frac{k_{1} \cdot d^{3}}{g}
$$


disminuida por la resistencia del aire: $k_{2} \cdot \mathbf{V}^{\prime 2} \cdot \mathbf{d}^{2}$, cuyo valor relativo es importante. En definitiva:

$$
P=\frac{m \cdot V^{2}}{2}-k_{2} \cdot V^{\prime 2} \cdot d^{2}
$$

y sustituyendo:

$$
P=\left(V^{\prime}-g \cdot t \cdot \operatorname{sen} \varphi\right)^{2} \frac{k_{1} \cdot d^{3}}{2 g}-k_{2} \cdot d^{2}
$$

Es decir, que la penetración de un grano es un producto de dos factores que dependen, respectivamente, de su velocidad de proyección y del diámetro; siendo $\mathbf{k}_{1}$ y $\mathbf{k}_{2}$ dos constantes de forma de los granos del árido.

Drögsler ha tratado de establecer la curva teórica de la probabilidad de rebote en función del diámetro de los granos del árido, experimentando con los de la granulometría representada por la línea $E$ de la figura 6 . Los resultados algunos irregulares, de estas experiencias, se traducen en la figura 15 y fueron realizados con las constantes:

- Superficie de proyección: vertical.

- Relación agua/cemento: a/c $=0,38$.

- Dosificación: $492 \mathrm{~kg} / \mathrm{m}^{3}$ de aglomerante.

- Aglomerante: $85 \%$ de cemento y $15 \%$ de trass.

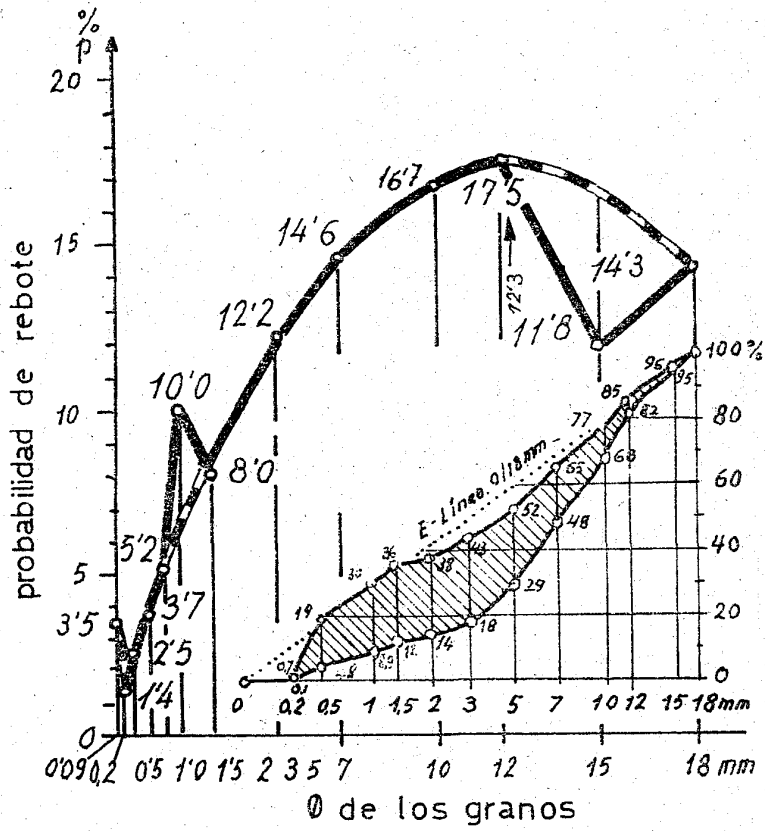

Fig. 15. Curva probabilidad de rechazo-tamaño del árido (Drögsler).

De las dos granulometrías de la parte interior de la figura 15: la superior corresponde sensiblemente a la línea $\mathbf{E}$ de la figura 6 , usando el material obtenido después de la proyección y lavado antes del cribado; y la inferior se refiere a la clasificación por cribado del rebote lavado, que fue aproximadamente un $10 \%$ del total. El eje vertical es el de probabilidades para los granos de diámetros indicados en el eje de abscisas. La curva, dibujada en trazo grueso, indica un máximo de probabilidad del 17,5\% para los granos de $\varnothing 12 \mathrm{~mm}$ y señala algunas irregularidades en los resultados, explicables por la dificultad de los ensayos, que condujeron al establecimiento de la ecuación teórica de segundo grado - que figura a continuación- de la probabilidad $\mathbf{P}$ del rechazo en función del diámetro de los granos:

$$
P=17,5-0,11(12,3-d)^{2} \text {; }
$$

con un máximo en el punto $(17,5 ; 12,3)$, baja hasta el $14,3 \%$ para los granos mayores experimentados, de $\varnothing 18 \mathrm{~mm}$, y con mayor rapidez aún del lado izquierdo del máximo, significando el esfuerzo de los granos pequeños por adherirse a los de mayor tamaño, durante el complejo proceso del gunitado que hemos tratado de aclarar.

Dadas las características especiales de la gunita y, principalmente el poco espesor en que generalmente se utiliza hay que tener un cuidado especial en la realización de las juntas de trabajo y en las de construcción, especial. mente si se trata de juntas que han de estar posteriormente sometidas a esfuerzos de compresión normales a las mismas.

La figura 16, añadida por nosotros a la traducción de las normas americanas R.P.S., es suficientemente ilustrativa sobre estos aspectos.

INCORRECTA
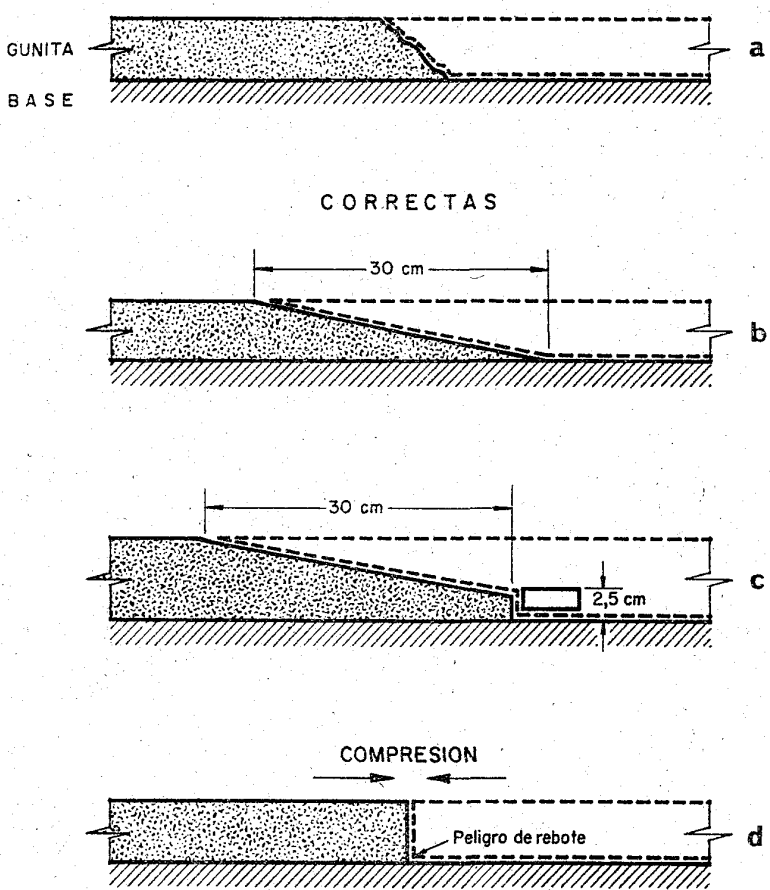

Fig. 16. Juntas de construcción engunitadas. 


\subsection{RESISTENCIA. ENSAYOS}

La resistencia final de la gunita, como se ha ido poniendo en evidencia a lo largo de estos comentarios, es semejante a la de los hormigones ordinarios para dosificaciones de cemento de la primera un poco más ricas, que se compensan con las economías en encofrados y colocación.

Un tipo de gunita que se puede considerar medio,

- $350 \mathrm{~kg} / \mathrm{m}^{3}$ de cemento,

- $\mathrm{a} / \mathrm{c}=0,40$,

- $\varnothing$ máximo del árido $=10 \mathrm{~mm}$,

- velocidad de proyección $=100 \mathrm{~m} / \mathrm{s}$,

- rebote $=20 \%$,

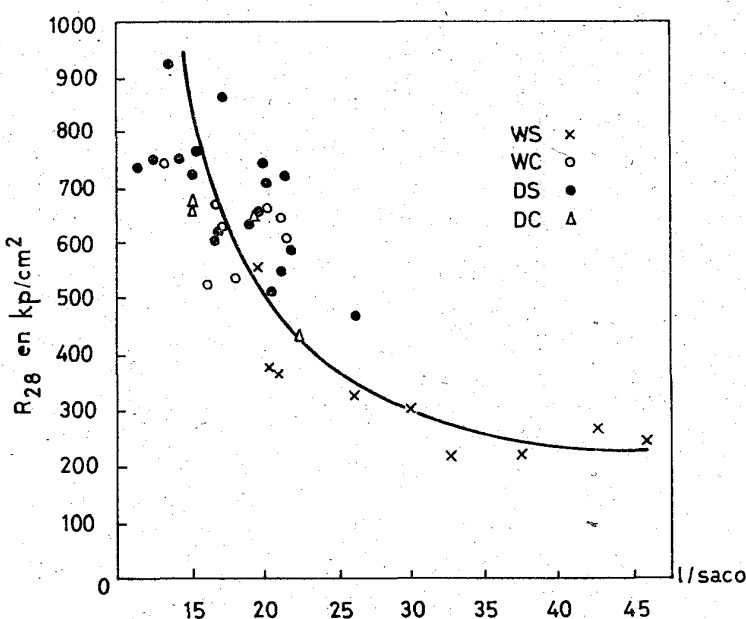

Fig. 17. Relación entre $R_{28}$ y a/c.

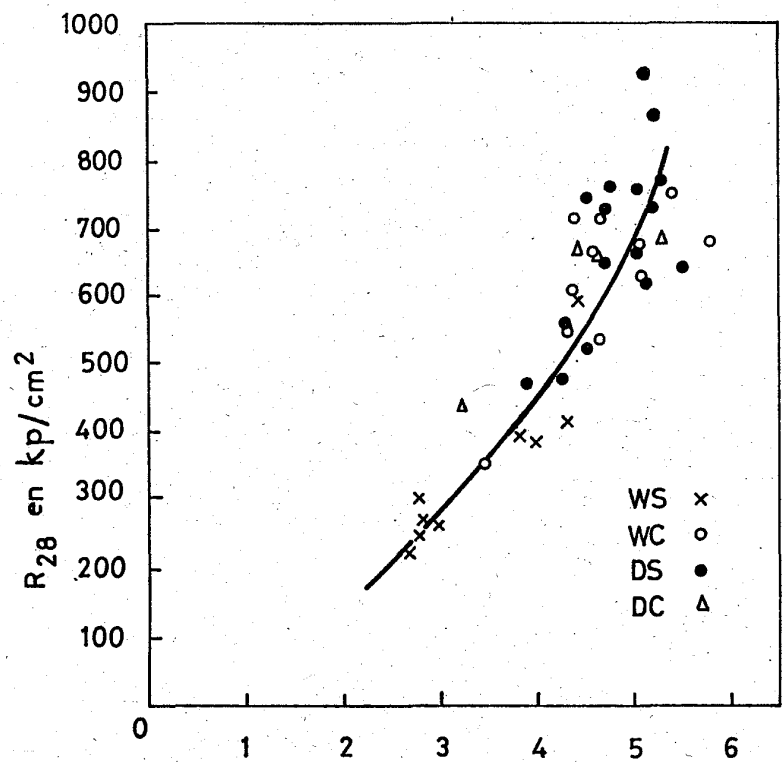

Fig. 18. Módulo de elasticidad: $0,0703 \times 10^{6} \mathrm{kp} / \mathrm{cm}^{2}$. debe dar unas resistencias, a la rotura por compresión a los 28 días, comprendidas entre 250 y $400 \mathrm{kp} / \mathrm{cm}^{2}$. La influencia de la composición y bondad del sistema de colocación de la gunita en esta variación, sobre todo la de este último factor, ha sido ya puesta en evidencia.

Las variaciones, que la composición de la mezcla introduce en la resistencia final, pueden estimarse sensiblemente paralelas a las muy conocidas de los hormigones ordinarios. G. Zynda, como consecuencia de ensayos oscilando alrededor de los valores indicados, estima que no debe utilizarse la gunita en ningún caso en que se precisen resistencias finales superiores a los $280 \mathrm{kp} / \mathrm{cm}^{2}$ de rotura a la compresión.

En unos extensos ensayos de laboratorio realizados por Litvin y Shideler y publicados por el American Concrete Institute en 1966, se han estudiado: las resistencias a la tracción, compresión y flexión; el módulo de elasticidad; la retracción de fraguado; la permeabilidad; la fluencia y los coeficientes de absorción y aislamiento de la gunita.

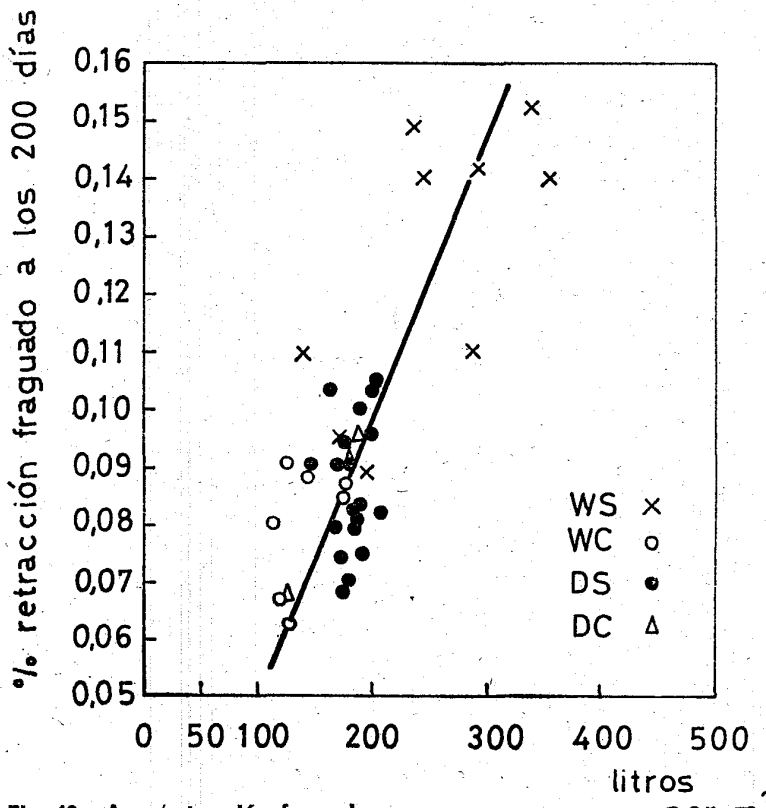

Fig. 19. Agua/retracción fraguado. por $\mathrm{m}^{3}$

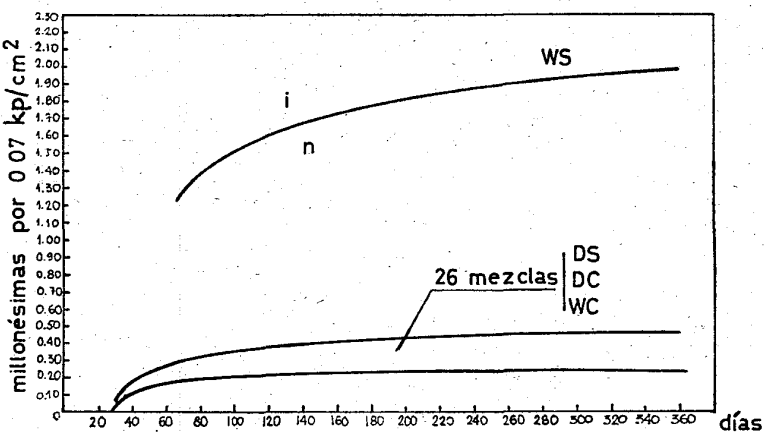

Fig. 20. Fluencia en $0,07 / 10^{6}$. 
Como consecuencia de estos ensayos con probetas cúbicas, de 7,5 cm de arista, prismáticas de 7,5 × 7,5 $\times 30,0$ centímetros principalmente, así como con gunitas por vía seca o vía humeda y con agregados finos (hasta $\varnothing \quad 0,10$ milímetros) y gruesos (hasta $\varnothing 25 \mathrm{~mm}$ ), se obtuvieron una serie de resultados que, prescindiendo de los valores numéricos, permitieron dibujar las curvas de: $R_{28}-a / c$ figura 17; $\mathbf{R}_{28}$-módulo de elasticidad, figura 19; retracción - contenido de agua, figura 19, y tiempo - fluencia, figura 20. En todas estas curvas, que hemos reducído a unidades métricas, las claves tienen la significación siguiente:

$$
\begin{aligned}
& \text { W S } ; \quad \text { gunita vía húmeda con áridos finos } \\
& \text { W C } ; 0: \text { gunita vía húmeda con áridos gruesos } \\
& \text { D S } ; \quad \text { gunita vía seca con áridos finos } \\
& \text { DC } ; \Delta: \text { gunita vía seca con áridos gruesos }
\end{aligned}
$$

Estos resultados de laboratorio deben apreciarse como indicativos solamente, ya que la formación de las probetas no reproduce exactamente las condiciones de puesta en obra.

La dispersión de los resultados de dos series de pruebas de resistencia a la rotura, con la curva teórica de probabilidad, ha sido hecha por Drögsler y se representa, para cada serie, en las dos curvas de la figura 21 , en la que los resultados de dos grupos de 76 y 78 probetas de gunita de composición en peso: $1 / 3,62$, con $382 \mathrm{~kg} / \mathrm{m}^{3}$, se agrupan de 40 en $40 \mathrm{kp} / \mathrm{cm}^{2}$ de resistencias a la rotura
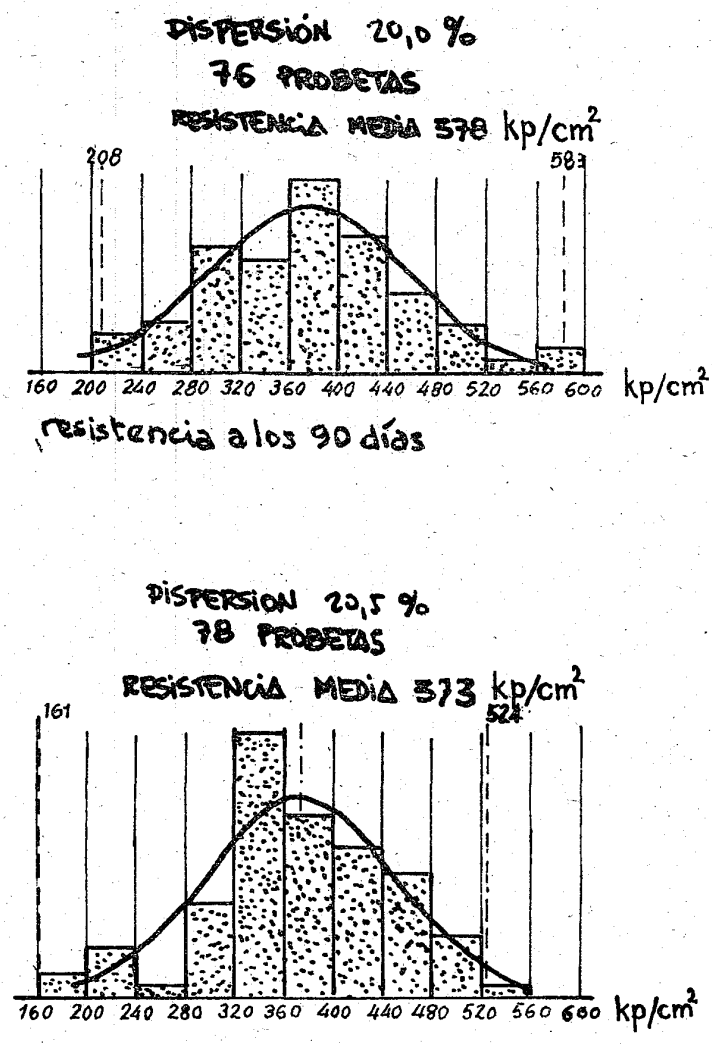

Fig. 21. Dispersión de las resistencias. a los 28 días. Las resistencias medias y dispersiones en \% para cada grupo fueron para el del gráfico superior: $378 \mathrm{kp} / \mathrm{cm}^{2} ; 20,0 \%$, y para el inferior: $373 \mathrm{kp} / \mathrm{cm}^{2}$ y $20,5 \%$.

También son muy satisfactorias las pruebas de impermeabilización y de ciclos hielo-deshielo llevadas a cabo por Drögsler que dan resultados muy comparables con los de los hormigones ordinarios. Estos resultados son interesantes por la positiva ampliación posible del uso de la gunita en climas extremos y para impermeabilización de túneles.

Se deduce de lo anterior que las diferencias de resistencia de la gunita con los hormigones son función principalmente de la distinta puesta en obra de una y otros. Y que, para la gunita, los resultados de laboratorio son menos fiables cuando se obtienen a partir de probetas sacadas de la proyección del material sobre superficles de ensayo. Más representativos son los de probetas procedentes de la proyección sobre bolsas de alambre en las condiciones reales de trabajo.

Para muestras cúbicas recogidas en obra, y en contra de lo que podía esperarse, los resultados de rotura de probetas por compresión no revelan diferencias acusadas en la dirección de proyección o en la normal a la misma y paralela a las superficies de contacto de capas sucesivas. Es muy: importante esta cualidad anixotrópica de la gunita, que se pone en evidencia en la figura 22

En resumen, para obras delicadas de gunita son indispensables los ensayos previos de calidad, seguidos de una detenida interpretación de los resultados que se obtengan. Es recomendable el atenerse a lo estipulado en los

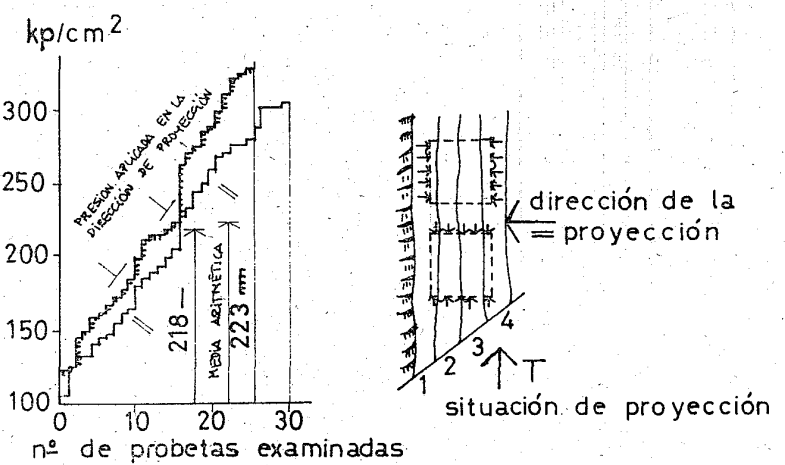

Fig. 22. Resistencia para distintas capas de proyección (Linder).

apartados 301,302 y 615 de las normas R.P.S. del A.C.I., a cuya traducción nos hemos referido reiteradamente. En general, los americanos recomiendan llevar el control de calidad mediante probetas recogidas en obra en las condiciones reales de trabajo y en Europa se emplean para este control los ensayos mediante penetrómetros.

Los comentarios anteriores pueden servir como una ayuda para la interpretación de estos resultados que guíe a la selección de la calidad y procedimientos de trabajo, aconsejables para cada obra. 


\section{Usos de la gunita}

\subsection{GENERALIDADES}

La gunita es un material preferible al hormigón ordinario en muchos casos de obras nuevas o reparaciones debido a sus propiedades, tales como: la destacable de su buena adherencia a otros materiales, y las restantes a que nos hemos referido en los párrafos precedentes, así como la de precisar menos encofrado con la consiguiente economía y el poder emplearla con un equipo de fabricación y colocación muy reducido.

El American Concrete Institute, como consecuencia de las contestaciones a un cuestionario sobre el tema del capítulo repartido entre las oficinas de obras públicas de carácter federal, estatal y municipal y empresas constructoras y oficinas de proyectos, hizo pública su conclusión de que la gúnita podía emplearse en los siguientes tipos de obras:

"Algunas clases de muros delgados; cúpulas y membranas delgadas, columnas en construcciones inclinadas, forros de los conductos de entrada y salida de los depósitos, piscinas, revestimientos de excavaciones, canales, revestimiento de muros inclinados de depósitos, salidas de humos y revestimiento de túneles.

Estabilización de taludes inclinados para protección de erosiones; cubiertas protectoras, sobre-excavaciones en roca para su estabilización antes del revestimiento (especialmente en túneles), protección superficial de los alambres de pretensado de depósitos, protección superficial de tuberías de hierro, revestimiento de excavaciones en minas de carbón, de gasoductos y de tanques de acero para protegerlos de la corrosión, revestimientos refractarios, revestimientos protectores del fuego, así como en otros tipos de construcciones nuevas en que no son efectivos los métodos de construcción convencional.

Reparación de estructuras de edificios y de chimeneas de hormigón, reparación de estructuras en contacto con el agua, pilotes, puentes, canales y túneles revestidos, depósitos y estructuras de muelles; uniones con el hormigón viejo en reparaciones de estructuras convencionales y obtención de superficies de textura rugosa.n

Por otra parte, el apartado 103 de las normas R.P.S. comporta una enumeración de los usos más frecuentes de la gunita clasificándolos en seis grupos, que transcribimos, aunque supongan una reiteración parcial de lo anterior.

"Los usos más frecuentes de la gunita son:

1. En estructuras nuevas: tejados (particularmente los de superficie curva o alabeada), muros, depósitos pretensados, revestimientos de depósitos y canales, piscinas, túneles, alcantarillas y pozos.

2. En recubrimiento: de fábricas de ladrillo, mampostería, hormigón, roca y acero.
3. En protección: de estructuras metálicas contra el fuego, así como en el refuerzo de las mismas.

4. En refuerzo: de muros de mampostería y hormigón.

5. En reparación: de hormigón deteriorado en estructuras, revestimientos de depósitos, presas, túneles, galerías, cajas de ascensores, superficies sometidas a la acción del agua y tuberías de gran sección, así como también en la reparación de estructuras dañadas por el fuego o los terremotos.

6. En revestimientos refractarios: de chimeneas, hornos y calderas."

Utilizando la clasificación anterior, se termina añadiendo algunas indicaciones útiles sobre casos particulares de empleo, en parte debidas a experiencias propias.

\subsection{EN ESTRUCTURAS NUEVAS}

En el apartado 3 se mencionan las posibilidades de la gunita de áridos ligeros utilizada como material estructural, principalmente en pisos, para disminuir su peso, con la consiguiente repercusión favorable en cimentaciones y en la calidad antisísmica de las edificaciones de gran número de plantas.

En las modernas estructuras laminares se usa frecuentemente la gunita. La figura 23 representa unas cubiertas parabólicas construidas con gunita, y se ha dibujado partiendo de la fotografía de una obra americana.

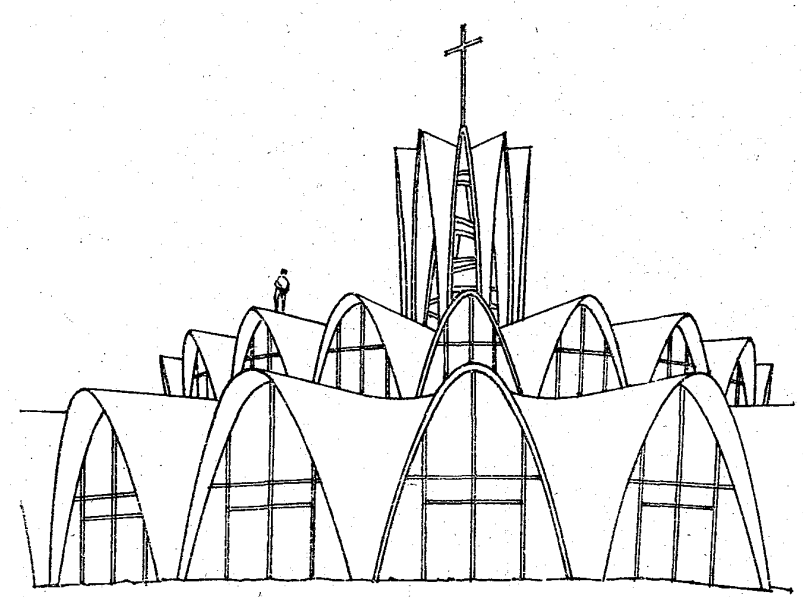

Fig. 23. Cubiertas parabólicas construidas con gunita. 
- Nosotros hemos reparado unos depósitos en Zaragoza construyendo una nueva lámina de gunita armada, utilizando como encofrado la antigua pared de hormigón ordinario que se encontraba superficialmente descompuesta.

También hemos empleado la gunita, con buenos resultados, como revestimiento de canales, principalmente en tramos excavados en roca.

En la construcción de piscinas, de forma irregular principalmente, se proyecta la gunita sobre armaduras colocadas directamente sobre la excavación. Esta actividad es el objeto de compañías especializadas y una clase de trabajo con características propias. Dichas compañías, muy numerosas en U.S.A. y otros países europeos, se han organizado también en nuestro país.

El gunitado directo sobre el terreno, en caso de excavaciones para cimientos, es una práctica cada vez más corriente como medio de estabilización permanente o temporal del terreno.

\subsection{EN TUNELES}

Merece un párrafo especial por la frecuencia de su empleo: a) como material estabilizante después de cada pegada; b) como revestimiento, sola o asociada al hor-

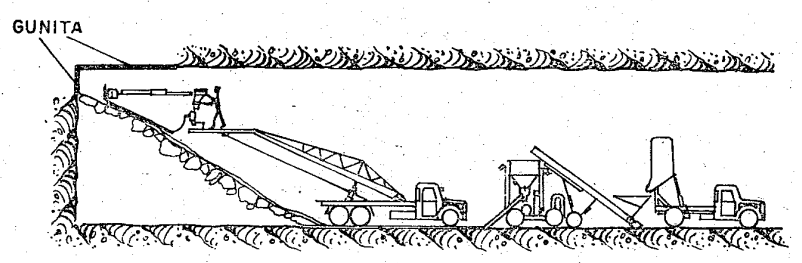

Fig. 24. Equipo de gunitado para estabilización en túneles después de las pegadas.

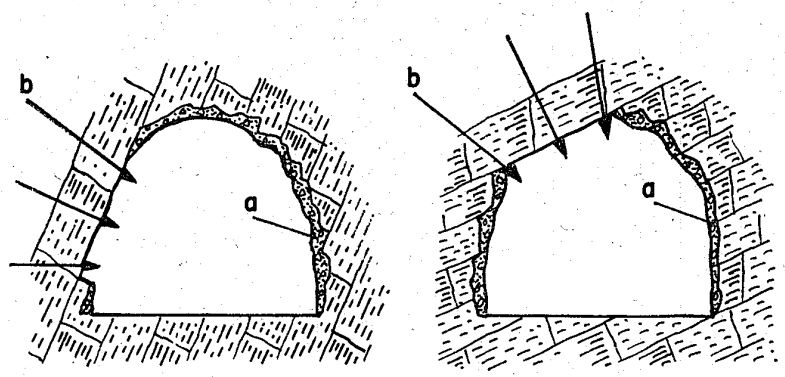

a) Gunita b) Anclajes

Fig. 25. Estabilización de galerías en túneles.

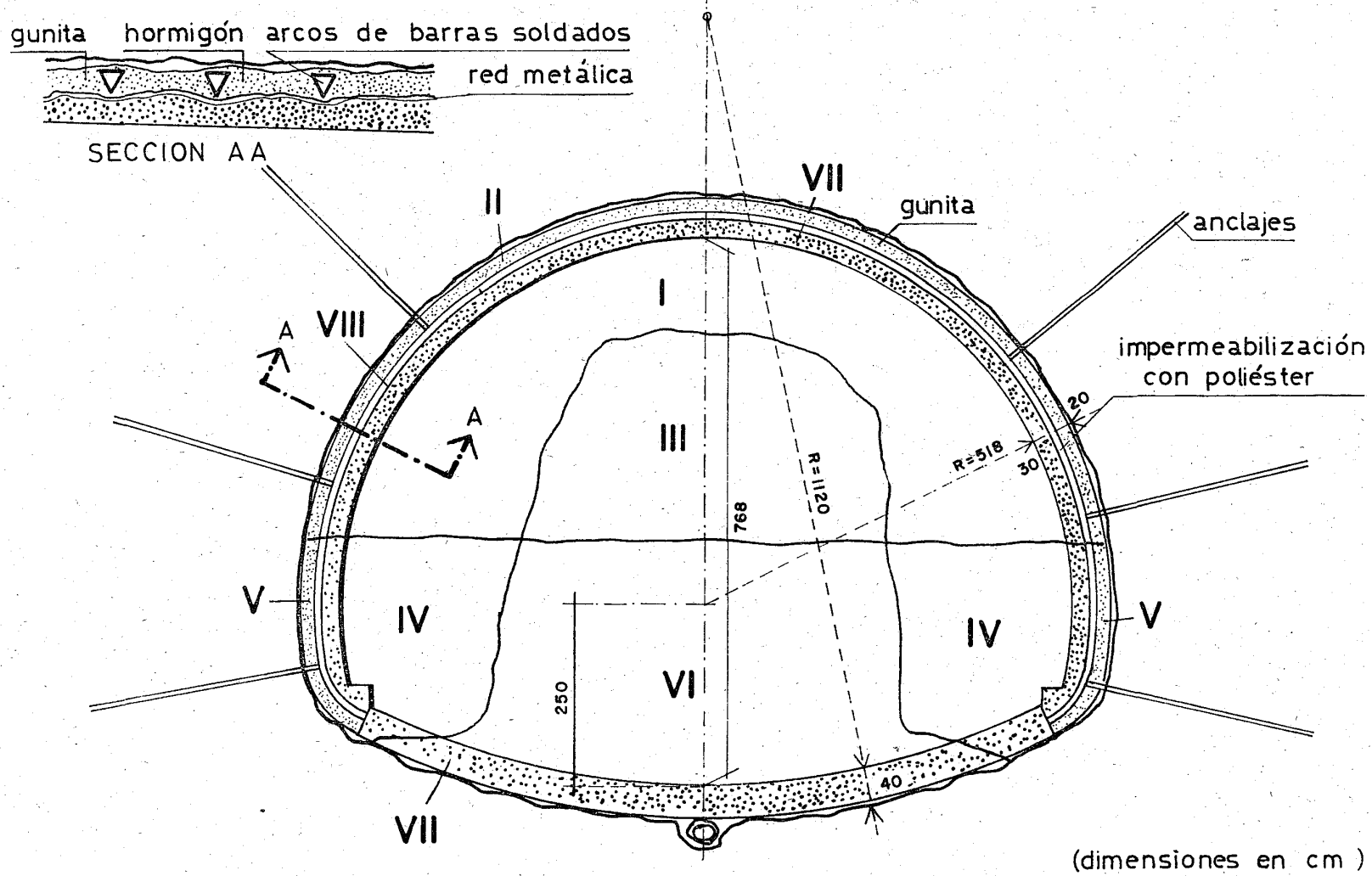

Fig. 26. Secuencia de construcción en un túnel para carretera en el sur de Austria. 
migón u otros materiales; c) formando parte del sistema de impermeabilización.

a) En el primer caso, la gunita se proyecta sistemáticamente, una vez saneado el frente y los costados de las excavaciones en roca, después de cada pegada. Se suelen utilizar en este caso equipos de proyección especiales, que permiten reanudar lo antes posible los trabajos de retirada de escombros y perforación. En la figura 24 se croquiza una instalación de gunitado de alimentación automática, en el curso de una operación de esta clase.

b) Es frecuente el empleo de la gunita como primer revestimiento de la totalidad de la sección de un túnel; en la mayoría de los casos embebiendo una armadura en la gunita y empleando además barras

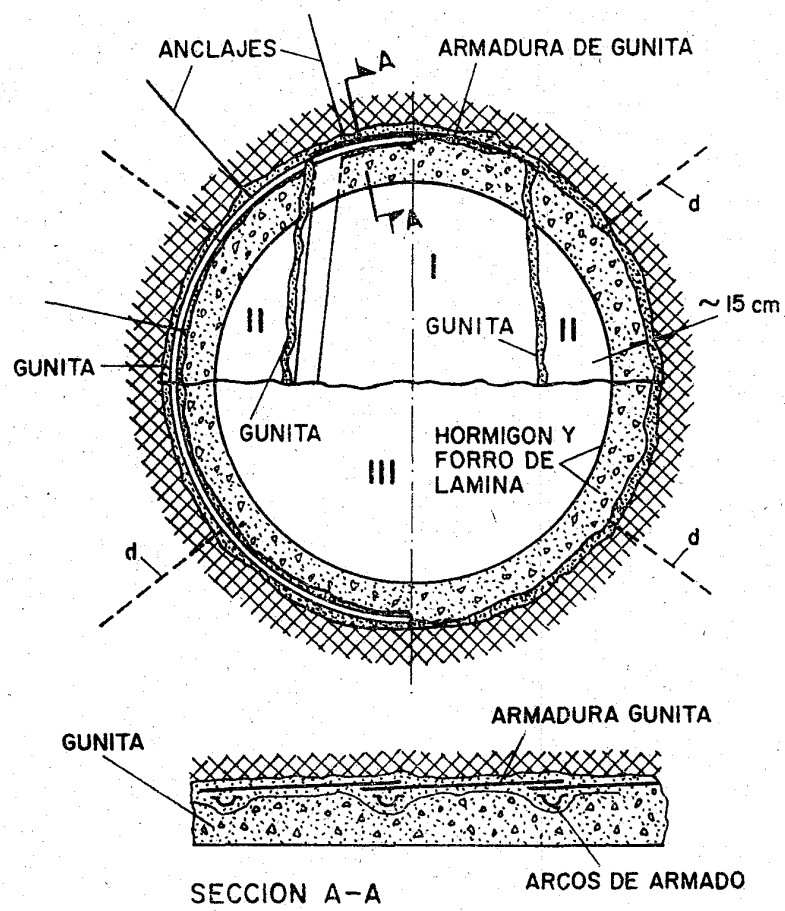

Fig. 27. Galería de Kaunertal (Tirol).

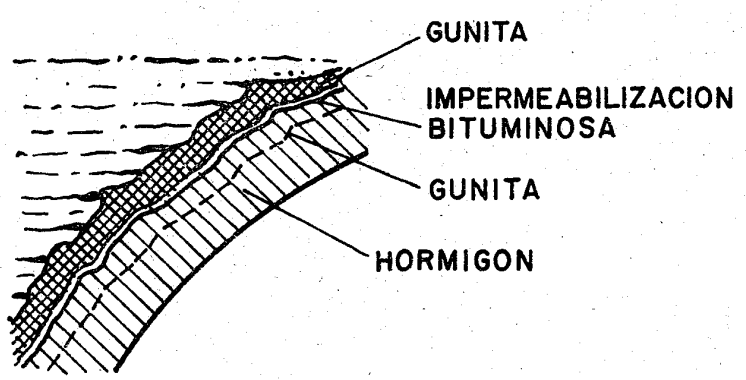

Fig. 28. Secciones de revestimiento de túneles (impermeabilización). de anclaje hincadas en la roca sin excavar, en las direcciones que aconseja la estratificación del terreno o si la superficie lisa del mismo dificulta la adherencia de la gunita. En la figura 25 se croquizan dos galerías de avance en las que está indicado el sistema de estabilización gunita + anclajes. En las figuras 26 y 27 se representan las secciones transversales y secuencias de excavación de un túnel y galería de presión, respectivamente, realizados en Austria en 1966 mediante este sistema, denominado método australiano. La forma de trabajo y el empleo provisional o definitivo de la gunita se adaptan naturalmente, en cada caso, a la naturaleza del terreno, a la forma y dimensiones de la sección y a la mayor o menor cantidad de filtraciones, a las que nos referimos en el párrafo siguiente al poner de manifiesto la cooperación del gunitado para contrarrestarlas.

Gunita, S. A., utilizó, no sin ciertas dificultades, un método análogo en el revestimiento de la galería de la central de la presa de Vilariño.

c) La gunita desempeña un papel de importancia en la impermeabilización temporal o definitiva de las excavaciones; en este último caso, asociada a materiales impermeabilizantes de uso tópico: láminas asfálticas o poliéster colocadas en forma de sandwich entre dos capas de gunita. Ultimamente se emplean, como materiales impermeabilizantes, resinas sintéticas modificadas para su fraguado en contacto del agua, y la proyección de mezclas en frío de látex de caucho con emulsiones asfálticas, simultáneamente con un coagulante. Este sistema presenta la ventaja de impermeabilizar cualquier superficie por irregular que sea y poco adaptable, en consecuencia, a otros materiales de impermeabilización preformados.

La impermeabilización es un problema siempre complejo que debe resolverse teniendo en cuenta las características y el volumen de la misma y los elementos disponibles, entre los que es indispensable un personal muy bien entrenado.

La figura 28 muestra las secciones de dos tipos de impermeabilización como los indicados, en los que puede observarse que la gunita es un elemento esencial de los mismos.

Digamos finalmente que el drenaje y las juntas del revestimiento son partes esenciales de la impermeabilización.

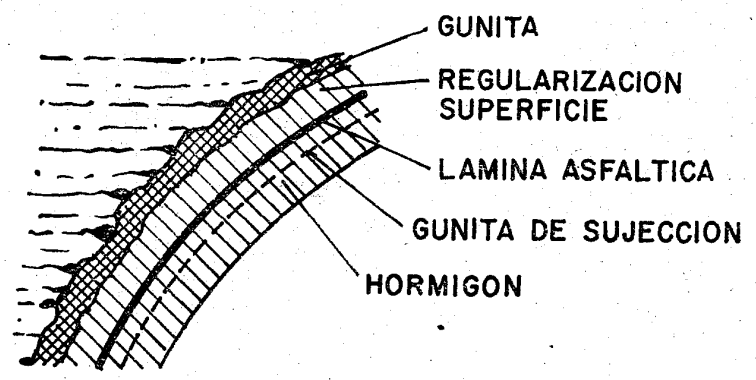


Con respecto a las últimas estamos de acuerdo con la opinión de $H$. Grob, quien estima que las juntas teóricamente perfectas y muy elaboradas, como la que se representa en la figura 29 , no suelen dar buenos resultados en la práctica y que la consecución de un buen drenaje debe ser preferente a la perfección de las juntas.

La figura 30 representa un detalle de la reparación del revestimiento del túnel de Niedershelten, construido en 1951-52 y cuya impermeabilización era inadecuada a pesar del espesor del hormigón. En dicha reparación se empleó asimismo la gunita (Hans Potthast).

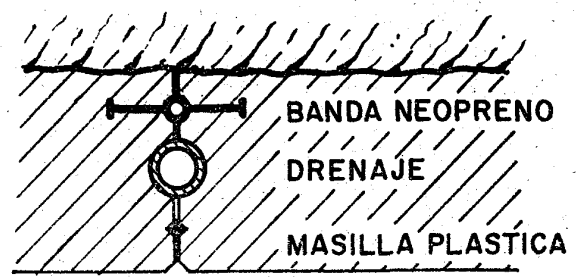

Fig. 29. Junta en la impermeabilización.

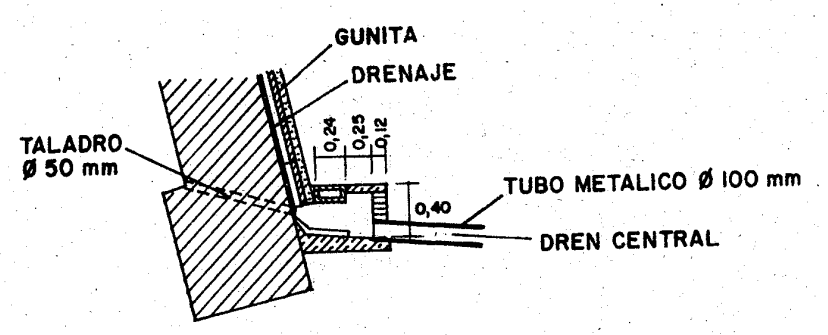

Fig. 30. Detalle de reparación de una impermeabilización.

\subsection{EN RECUBRIMIENTOS}

Como caso muy especial, que requiere técnicas de colocación singulares, mencionamos en este apartado el empleo frecuente de la gunita como recubrimiento y protección antioxidante de los alambres de postensado exterior en depósitos de hormigón cilíndricos. La dificultad principal reside en que estas armaduras, constituidas por alambres de muy pequeño diámetro en contacto con el hormigón, deben quedar envueltas por la gunita.

Nosotros hemos recubierto y protegido dos tanques para agua de este tipo, en la factoría de Butano, de Sevilla, empleando la gunita con buenos resultados. La totalidad del trabajo se llevó a cabo con el mismo equipo de gunitado, y la secuencia de operaciones fue la siguiente:

a) Limpieza mediante chorro de arena de hormigón y alambre.

b) Aplicación de una lechada de cemento y agua a razón de $3 \mathrm{~kg} / \mathrm{m}^{2}$. c) Antes de que seque la capa b), qunitado de una mezcla con arena fina y proporción $1 / 3$ en peso; esta capa tenía un espesor de $10 \mathrm{~mm}$ más el del $\varnothing$ del alambre de tensado. Se denomina "flash coating" y debe limpiarse para quitar los restos de lechada de cemento.

d) Gunitado de una nueva capa, de $10 \mathrm{~mm}$ de espesor, de gunita de granulometría normal y dosificación $1 / 3$.

e) Después de la comprobación acústica de la adherencia de las capas anteriores, nueva aplicación de otra capa final de gunita, de dosificación $1 / 3,5$, de otros $10 \mathrm{~mm}$ de espesor, "finish coat", a la que se dio un acabado con llana, aplicando posteriormente una capa de pintura superficial.

El espesor final del recubrimiento fue de $3 \mathrm{~cm}$ más el $\varnothing$ del alambre, y todas las capas se curaron mediante pulverización de agua; la última durante 7 días.

El proceso anterior se simplificó para uno de los tanques, haciendo, en lugar de las dos aplicaciones c) y d), una sola de espesor $20 \mathrm{~mm}+\varnothing$.

La capa final de pintura, vinílica o a base de caucho aplicada en dos manos, mejora el aspecto, tapa las grietas de retracción e impermeabiliza la superficie.

\subsection{EN REVESTIMIENTOS REFRACTARIOS}

El coeficiente de conductividad térmica de la gunita es menor, debido a su estructura porosa, que el de los hormigones ordinarios. Esta propiedad fue puesta en evidencia por Livovich, quien la midió en función de la densidad

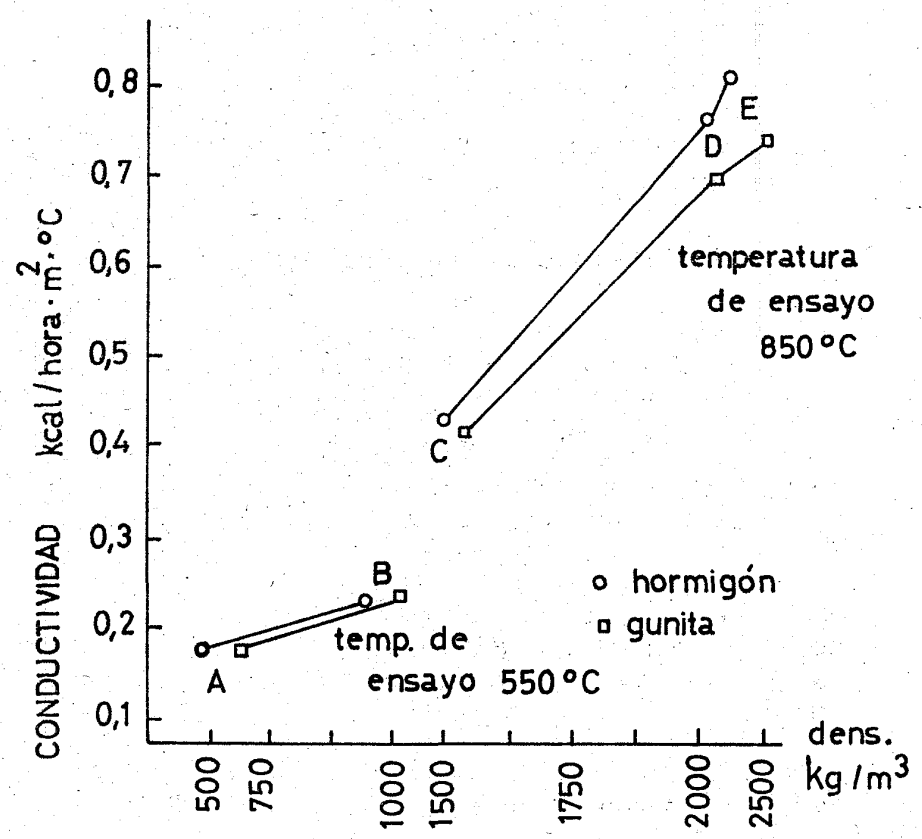

Fig. 31. Densidad/conductividad para hormigones y gunitas A, B, C, D. E. 
de la gunita. Al hablar de estructura porosa nos referimos a que, para cantidades iguales de aice ocluido, éste se encuentra en la gunita subdividido en mayor número de burbujas de menor tamaño y mejor repartidas que en el hormigón ordinario. De esta peculiaridad se deduce la buena clase de aislamiento térmico que ofrece la gunita y abre para la misma un campo de aplicación para obtener recubrimientos refractarios, en el que personalmente no tenemos experiencia. En la figura 31 se ven los resultados comparativos, del poder aislante de mezclas, con distintas clases de agregados ligeros, entre hormigones colocados a mano y gunitados, para cinco tipos de agregados ligeros (A, B, C, D, E) y dos temperaturas de ensayo. En la figura hemos hecho el cambio de unidades correspondiente.

\subsection{EN REPARACION DE CANALES}

En varios casos de refuerzo de revestimientos de canales hemos utilizado, con buenos resultados, una capa adicional de gunita sobre el revestimiento anterior descompuesto. En operaciones de este tipo son de tener en cuenta las circunstancias siguientes:

a) La dificultad de operación por tratarse de trabajos lineales, que lleva consigo el acopio de materiales, desplazamientos de equipo y suministros de agua, aire y energía.

b) La necesidad de una limpieza a fondo del material subyacente, separando las partes del mismo rotas 0 descompuestas.

c) La instauración de nuevas juntas de dilatación, teniendo en cuenta la posición de las anteriores y su actividad durante la vida de la obra.

d) Necesidad de un espesor mínimo $3-5 \mathrm{~cm}$ del nuevo revestimiento, y si éste debe armarse o no con una tela metálica, de tipo gallinero preferentemente.

e) Extremar los cuidados de curado posterior y decidir sobre la conveniencia del uso de un aditivo que mejore la adherencia a la base anterior deteriorada.

\subsection{EN REPARACION DE ESTRUCTURAS}

Puede decirse que una de las más importantes aplicaciones de la gunita es en la reparación de estructuras de hormigón alteradas por esfuerzos accidentales, como sismos, y en los casos muy frecuentes de desintegración, más o menos profunda de estructuras, debida a la oxidación de las armaduras, con el consiguiente aumento de volumen y producción de roturas que lleguan a comprometer la estabilidad del conjunto.

Hemos llevado a cabo un interesante trabajo de esta clase en la reparación de los pilotes de hormigón armado del pantalán para los tubos de refrigeración de la central térmica de FECSA, en Badalona.

Sirvió de guía a nuestra operación el informe de Fluss y Gibson acerca de la reparación de un muelle sobre pilotes realizado en el puerto de San Francisco, U.S.A., ál que corresponde, adaptada de una fotografía, la figura 32 , que tomamos de la traducción de las normas R.P.S.
Las condiciones de operación tuvieron naturalmente que adaptarse a las condiciones locales y al material disponible, y consistieron en el empleo de:

- Dosificación: $400 \mathrm{~kg} / \mathrm{m}^{3}$.

- Aditivo: Feb-Gun al 3\% en peso del cemento.

- Arido: Siliceo de granulometría aproximada:

\begin{tabular}{|c|c|}
\hline Criba U.S.A. & \% que pasa \\
\hline 4 & 100 \\
8 & $80-90$ \\
16 & $55-60$ \\
30 & $30-33$ \\
50 & $10-18$ \\
100 & $4-5$ \\
200 & 1 \\
\hline
\end{tabular}

- Equipo de gunitado: ALIVA-400.

- Secuencia de operación:

Saneamiento del hormigón manchado por el óxido.

Limpieza de armaduras y sustitución de estribos y de algunas barras principales, mediante soldadura.

Limpieza con chorro de arena.

Gunitado por capas hasta recubrir $5 \mathrm{~cm}$ las armaduras.

Curado con agua durante 7 días.

Pintura superficial con emulsión asfáltica.

La reparación, durante la temporada estival de 1969, extendió a la mitad de la longitud del pantalán y afectó, en mayor o menor medida a todos los pilotes y vigas de enlace y sostenimiento del piso del pantalán. No ha transcurrido aún tiempo suficiente para tener un criterio definitivo de los resultados; pero desde el principio se vio la conveniencia económica comparativa de esta reparación con la de clavado de unos pilotes y unión de los mismos a la estructura dañada.

\subsection{MEDICION DE GUNITADOS}

Cuando la operación de gunitado va a realizarse sobre una superficie plana, cilíndrica o definible geométricamente, el volumen de material a proyectar es igual a:

superficie $\times$ espesor $+\%$ de rebote $=$ volumen obra;

en el que todos los componentes son conocidos a priori y fácilmente medibles los dos primeros. La posición de la superficie es conocida y las pérdidas por rebote apreciadas fácilmente por los resultados obtenidos, con el mismo equipo y mano de obra que vayan a emplearse, en condiciones de trabajo semejantes. No hay, pues, indeterminación que justifique error alguno en la estimación del precio de costo (que puede darse por $\mathrm{m}^{3}$ de material, o por superficie para un espesor dado), ni para la medición y abono posterior del trabajo realizado. 
Sin embargo, en los casos muy frecuentes de gunitado de excavaciones a cielo abierto, o en túneles, los tres componentes de la ecuación anterior llevan consigo, por motivos diversos, un cierto grado de indeterminación. EI problema de precio de costo y el de medición de obra realizada acumulan a veces esta doble indeterminación en lugar de compensarla.

Analicemos, aunque sea ligeramente, este problema y sus posibles soluciones:

Superficie: Es siempre mayor que la teórica y el exceso resulta aleatorio. Una estimación apriorística puede conducir a errores por exceso o defecto.

Espesor: Sólo en los puntos en que sea mínimo puede fijarse para la secuencia de operación. En el resto de la superficie, el necesario redondeamiento exterior de la misma acarrea el empleo de exceso de material.

Rebote: Depende de la inclinación de la superficie de modo inversamente proporcional al grado de bondad de la operación.

Fácilmente se llega a la conclusión de que el material debe estimarse en la alimentación, aplicando un \% de rebote que sea garantía de una buena operación. En cuanto se pase de un \% de rebote superior al preestimado, el material proyectado debe disminuirse, para su abono, en este exceso.

No creemos que pueda, con garantía mutua entre contratista y administración, procederse de otro modo menos aleatorio.

Queda pon fijar - lo que debe hacerse apriorísticamente como consecuencia del tipo de trabajo - el \% máximo de rebote admisible, que obligue al contratista a adoptar un buen sistema de trabajo que lo reduzca.

Este \% de rebote se puede fijar tomando en cuenta las indicaciones siguientes:

Standard Practice for Shotcreting A.C.I. 1966.

Rebote en pisos o lozas .................. 5 al $15 \%$ Rebote en muros verticales o inclinados ... 15 al $30 \%$

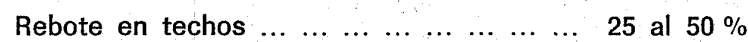

Según el ángulo de inclinación con la horizontal, figura 14 , Linder hace variar linealmente desde $0^{\circ}$ a $90^{\circ}$ el rebote admisible como sigue:

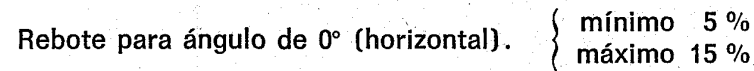

Variando linealmente hasta:

Rebote para ángulo de $90^{\circ}$ (vertical). $\left\{\begin{array}{l}\text { mínimo } 20 \% \\ \text { máximo } 30 \%\end{array}\right.$

Drögsler admite una variación, para los límites máximo y mínimo aceptables para el rebote en función de la inclinación de la proyección, de forma aproximadamente parabólica, pasando por los puntos:

Inclinación (grados): $\quad \begin{array}{lllll}0 & 30 & 60 & 90\end{array}$

$\begin{array}{lllll}\% & \text { admisible para rebote: } 10-12 & 17,5-21,5 & 19-24 & 20-25\end{array}$

Asimismo Drögsler estima, de modo aproximadamente parabólico, la variación del rebote con la distancia de proyección.
Entre los límites extremos de: 0,75 y $1,25 \mathrm{~m}$, puede muy aproximadamente estimarse una variación lineal de los siguientes valores del rebote:

Distancia de proyección (m) : $\begin{array}{cccc}0,75 & 1,00 & 1,25\end{array}$

Mínimo de rebote $(\%): \quad 25 \quad 10 \quad 25$

\subsection{CONCLUSIONES}

En las líneas precedentes se han expuesto algunas propiedades de los distintos tipos de gunitados posibles y la influencia en su calidad de las variables: composición, ejecución y puesta en obra. Toda la exposición, que está basada en los resultados recientes de la experiencia de destacados especialistas y en alguna parte también en la propia, debe mirarse como una ampliación de las recomendaciones de carácter pragmático contenidas en las normas americanas "Recommended Practice for Shotcreting" vertidas al castellano por nosotros y publicadas con el título de NORMAS PARA LA EJECUCION Y EMPLEO DE LA GUNITA, 1970, que siguen a estas notas.

Tenemos la esperanza de que el conjunto de información pueda ser útil para quienes empleen tópicamente este material y aún que pueda inducir a algunos ingenieros a su uso como alternativa de otros materiales, e incluso al empleo de la gunita en la solución de nuevos problemas constructivos.

Unos cuantos hechos fundamentales han contribuido en los países de técnicas de construcción avanzadas, entre los que el nuestro tiene por derecho propio un justo lugar, al auge, en los años de la postguerra, del empleo de este material que desde su aparición a principios del siglo se había usado solamente en aplicaciones muy determinadas. Han contribuido a este aumento del empleo de la gunita una serie de factores, implícitos en estos comentarios:

- Las mejoras introducidas en el equipo de aplicación.

- La posibilidad de proyectar mezclas de áridos de mayor tamaño hasta de $\varnothing 30 \mathrm{~mm}$, que constituyen verdaderos hormigones.

- El desarrollo del procedimiento de gunitado por "Vía húmeda", preferible en muchos casos al clásico de "vía seca".

- El ensayo con éxito de su empleo en las técnicas de revestimiento de túneles y excavaciones.

- La disposición de personal bien entrenado en las técnicas de operación.

- La mejora del conocimiento de la tecnología de este material, como consecuencia de los resultados de su aplicación y de los ensayos e investigaciones de laboratorio.

- El disponer de Normas oficiales para su empleo.

Insistimos aquí, para terminar, en la sorpresa por el silencio de nuestra reciente "Instrucción para el proyecto y ejecución de obras de hormigón en masa o armado", vigente a partir de septiembre de 1970 , con respecto a la gunita; que no es en realidad otra cosa que un hormigón puesto en obra por procedimientos especiales y cuyo campo de aplicación ha tenido un espectacular crecimiento en los últimos años. 


\section{Normas para la ejecución y empleo de la gunita}

(Standard Practice for Shotcreting. A.C.I. 1966)

\subsection{GENERALIDADES}

\subsubsection{Introducción}

La gunita es un mortero u hormigón, transportado a través de manguera y proyectado neumáticamente, a gran velocidad, sobre una superficie. La fuerza del impacto compacta el material. Se utiliza generalmente una mezcla relativamente seca y al material no se afloja ni desprende, aun sobre paramentos verticales o techos.

El hormigón proyectado ha recibido varias denominaciones: gunita, mortero u hormigón aplicado neumáticamente, P.A.M. *, hormigón proyectado, hormigón aplicado por «spray ", mortero u hormigón soplado, hormigón cañoneado y otros. Si bien el término a Mortero aplicado por presión neumática» fue utilizado en el título de la especificación A.C.I. Standard 805-51, la denominación aHormigón proyectado " fue la utilizada en el contenido del informe **.

La gunita es un material adecuado para numerosos tipos de construcciones y reparaciones. Sin embargo, su calidad y rendimiento dependen en gran parte: de las condiciones en que se coloque, de lo adecuado del equipo $y$, muy especialmente, de la competencia del personal que ejecute la obra.

Estas normas reflejan los conocimientos adquiridos sobre el tema desde que fueron publicadas, en 1951, las anteriores A.C.I. Standard: «Recomendaciones prácticas para la aplicación de mortero por medio de presión neumátican. Abarcan el proceso muy utilizado de mezcla en seco, en el cual la mayor parte del agua se añade en la boquilla; y también el recientemente introducido de mezcla en húmedo, en el cual todos los materiales, incluso el agua, se mezclan antes de entrar en la manguera de transporte. De un modo general, estas normas deben seguirse en las construcciones en que se emplee la gunita.

Las recomendaciones especiales para construcción de depósitos y otras aplicaciones, se encuentran en diversas publicaciones. Por ejemplo: en el Simposio del A.C.I. sobre gunita se trató del tema de construcción de depósitos y se está preparando, además, la publicación de los fascículos sobre el tema.

\subsubsection{Tipos de gunita}

Existen dos tipos de gunita que se designan con los nombres de: gunita obtenida por el proceso de mezcla en seco y por el de mezcla por vía húmeda.

- Pneumatically Applied Mortar.

- En nuestra traducción emplearemos la palabra gunita, que es la comúnmente usada en España para designar el mortero u hormigón proyectado. a) Proceso de mezcla en seco.

Comprende las fases siguientes:

1. Mezcla uniforme del cemento y arena húmeda.

2. La mezcla cemento-arena entra en un alimentador mecánico especial o cañón, que se denomina equipo de entrega.

3. La mezcla llega a la manguera de transporte por medio de una rueda alimentadora o distribuidora.

4. El material es transportado, mediante aire comprimido, a lo largo de la manguera hasta una boquilla especial. La boquilla contiene, en su parte interior, una pieza perforada a través de la cual se introduce agua a presión, que se mezcla intimamente con la mezcla árido-cemento.

5. El mortero sale por la boquilla a gran velocidad hacia la superficie que se quiere gunitar.

Este proceso se ha utilizado durante casi 50 años para la aplicación de mezclas de mortero en construcciones de muchas clases.

b) Proceso de mezcla por vía húmeda.

Comprende las siguientes operaciones:

1. Todos los componentes, incluyendo el agua de amasado, se mezclan íntimamente.

2. El mortero u hormigón se introduce en la cámara del equipo de entrega.

3. La mezcla se dosifica en el interior de la manguera transportadora y es conducida, por aire comprimido u otros medios, a la boquilla de salida.

4. Se inyecta aire comprimido adicional en la boquilla de salida, con objeto de aumentar la velocidad y mejorar la calidad del gunitado.

5. El mortero u hormigón es lanzado por la boquilla a gran velocidad contra la superficie a gunitar.

Se han aplicado morteros mediante este procedimiento en un considerable número de obras, durante los últimos 10 años. En los últimos 5 años se han aplicado, utilizando también este sistema, mezclas especiales de hormigón con áridos de hasta $19 \mathrm{~mm}\left(3 / 4^{\prime \prime}\right)$.

\section{c) Comparación de los procesos.}

La gunita fabricada y aplicada por cualquiera de los dos procedimientos anteriores puede emplearse en construcciones de tipo general. Sin embargo, diferencias en el coste de los equipos, en su mantenimiento, y en las características de puesta en obra, pueden hacer uno u otro sis- 
tema más recomendable para casos concretos. En la tabla 102 (c) se indican las diferencias características de cada proceso, que deben ser tenidas en cuenta para esta selección.

TABLA 102 (c). Comparación de las principales características de los procesos de mezcla en seco y por vía húmeda.

\begin{tabular}{l|l}
\hline \multicolumn{1}{c|}{ Mezcla en seco } & \multicolumn{1}{c}{ Mezcla por vía húmeda } \\
\hline $\begin{array}{l}\text { Se tiene en la boquilla } \\
\text { el control del agua y } \\
\text { la consistencia de la } \\
\text { mezcla. }\end{array}$ & $\begin{array}{l}\text { 1. } \begin{array}{l}\text { La adición de agua se } \\
\text { controla en el equipo } \\
\text { de transporte y puede } \\
\text { ser medida exacta- } \\
\text { mente. }\end{array} \\
\text { 2. Más adecuado para el } \\
\text { manejo de las mezclas } \\
\begin{array}{l}\text { que contienen agrega- } \\
\text { dos porosos y ligeros. }\end{array}\end{array} \begin{array}{l}\text { 2. Mayor seguridad de } \\
\text { que el agua se mez- } \\
\text { cla totalmente con los } \\
\text { otros componentes }\end{array}$ \\
$\begin{array}{l}\text { Como consecuencia, } \\
\text { hay menores pérdidas } \\
\text { por rebote. } \\
\text { 3. Permite una mayor lon- } \\
\text { gitud de la manguera } \\
\text { de entrega. }\end{array}$ & $\begin{array}{l}\text { Se produce menos pol- } \\
\text { vo durante la opera- } \\
\text { ción. }\end{array}$ \\
\hline
\end{tabular}

\subsubsection{Usos de la gunita}

El empleo de la gunita en sustitución del hormigón normal es ventajoso en muchos casos de obras nuevas o reparaciones. Los ingenieros con conocimientos y experiencia de este material, deben decidir cómo y cuándo debe usarse la gunita.

Las razones económicas a favor de su empleo se derivan de que precisa menor superficie de encofrados que el hormigón convencional, así como un equipo, para fabricación y colocación, más manejable y barato. La gunita tiene, además, una excelente adherencia sobre gran número de materiales, propiedad ésta de la mayor importancia.

Los usos más frecuentes de la gunita son:

1. En estructuras nuevas: tejados (particularmente los de superficie curva o alabeada), muros, depósitos pretensados, revestimientos de depósitos y canales, piscinas, túneles, alcantarillas y pozos.

2. En recubrimiento: de fábricas de ladrillo, mampostería, hormigón, roca y acero.

3. En protección: de estructuras metálicas contra el fuego, así como en el refuerzo de las mismas.

4. En refuerzo: de muros de mampostería y hormigón.

5. En reparación: de hormigón deteriorado en estructuras, revestimientos de depósitos, presas, túneles, galerías, cajas de ascensores, superficies sometidas a la acción del agua y tuberías de gran sección. Así como en la reparación de estructuras dañadas por el fuego o los terremotos.

6. En revestimientos refractarios: de chimeneas, hornos y calderas.

\subsubsection{Propiedades de la gunita}

Empleado correctamente, la gunita es un material estructural resistente, duradero y con una buena adherencia sobre hormigón, mampostería, acero y otros materiales. Estas excelentes propiedades exigen un proyecto y supervisión adecuados y gran destreza y cuidado del personal que ejecute la obra.

Son fáciles de encontrar numerosas referencias de obras de gunita, pero con escasos datos técnicos, que muestran, además, una gran dispersión de valores. Ello es debido a la gran diferencia de calidad de las obras y a la dificultad de obtención de muestras representativas para ensayo.

En la gunita, ya colocada, la relación a/c debe oscilar entre 0,35 y 0,50 ; proporción algo más baja que la de los hormigones ordinarios.

Las propiedades mecánicas y físicas de una buena gunita son semejantes a las de los morteros y hormigones convencionales de la misma composición. Los valores más frecuentes de la resistencia a la rotura a los 28 días oscilan entre $200 \mathrm{kp} / \mathrm{cm}^{2}(3.000 \mathrm{psi}) *$ y $500 \mathrm{kp} / \mathrm{cm}^{2}$ (7.000 psi), aunque en agunos ensayos se han encontrado resistencias hasta de $700 \mathrm{kp} / \mathrm{cm}^{2}$ (10.000 psi). Se recomienda no exigir resistencias superiores a $280 \mathrm{kp} / \mathrm{cm}^{2}$ (4.000 psi), excepto en obras cuidadosamente proyectadas y en las que se prevea una excelente ejecución.

La retracción de fraguado de la gunita depende en gran parte de su dosificación, y oscila entre el 0,06 y el $0,1 \%$. Estos valores son algo mayores que los de los hormigones pobres empleados en secciones grandes, con agregados mayores y dosificaciones de cemento más bajas. La mayor importancia de la retracción obliga a establecer juntas más próximas.

El comportamiento de la gunita, en ensayos de laboratorio y en probetas expuestas a la intemperie, es en general buena. Sin embargo, se aconseja proteger las reparaciones hechas con gunita y expuestas a heladas 0 en contacto con aguas agresivas, mediante aplicaciones de aceite de linaza en caliente u otra capa de protección, con objeto de impedir la entrada de la humedad a través de las grietas de retracción. Cuando se aplica la gunita sobre una superficie inestable o sucia, la falta de adherencia puede ocasionar su desprendimiento después de algunos años.

\subsection{MATERIALES}

\subsubsection{Cemento}

\section{a) Cemento portland.}

El cemento portland que se emplee para gunitados debe cumplir las condiciones A.S.T.M., C 150, C 175, C 205 ó C $240^{* *}$. Cuando se utilicen áridos que puedan reaccionar con los álcalis del cemento, deberá emplearse un cemento de bajo contenido en álcalis. Si la gunita ha de quedar expuesta a la acción de terrenos o aguas sulfatadas, debe

- Como en el texto inglés hemos utilizado valores redondos aproximados. La equivalencia exacta es: $1 \mathrm{psi}=0,070307 \mathrm{kp} / \mathrm{cm}^{2}$

* Equivalentes a las de los tipos P-250, P-350 y P-450 del vigente Pliego de Condiciones para la Recepción de Conglomerantes Hidráulicos de $6 / 5 / 64$ 
usarse cemento del tipo $V^{*}$. Cuando por razones estructurales se requieran altas resistencias iniciales, deben emplearse del tipo III **.

\section{b) Cemento aluminoso.}

Es un cemento de endurecimiento rápido, que debe preferirse a los cementos ordinarios cuando se precisen recubrimientos resistentes al calor, como los refractarios. Es además muy resistente a la acción de ciertos ácidos. Su empleo requiere algunas precauciones debido al alto calor inicial de hidratación. Las diferentes marcas de este cemento difieren además en composición y características, debido a las diferencias en materias primas y procesos de fabricación, circunstancia que debe ser tenida en cuenta.

\subsubsection{Aridos}

La arena empleada para gunita ha de cumplir con las condiciones para agregados finos de la norma A.S.T.M. C 33 "Specifications for concrete Aggregates". La granulometría adecuada es la de la tabla 202 (a).

TABLA 202 (a). Granulometría de los áridos finos.

\begin{tabular}{c|c|c}
\hline $\begin{array}{c}\text { Tamaño del tamiz } \\
\text { U.S.A. Standard de } \\
\text { malla cuadrada }\end{array}$ & $\begin{array}{c}\text { Medidas de tamices } \\
(\mathrm{mm})\end{array}$ & $\begin{array}{c}\% \text { en peso que pase } \\
\text { por el tamiz }\end{array}$ \\
\hline & & \\
$3 / 8 "$ & 9,52 & 100 \\
Núm. 4 & 4,76 & $95-100$ \\
Núm. 8 & 2,38 & $80-100$ \\
Núm. 16 & 1,19 & $50-85$ \\
Núm. 30 & 0,595 & $25-60$ \\
Núm. 50 & 0,297 & $10-30$ \\
Núm. 100 & 0,149 & $2-10$ \\
\hline
\end{tabular}

Sin embargo, arenas que no cumplan con esta granulometría pueden utilizarse si se obtienen con ellas buenos resultados en las pruebas anteriores a su empleo, pruebas indicadas en el capítulo 3.3. Las arenas para acabados, recubrimientos superficiales ligeros y otras aplicaciones especiales, pueden ser más finas que las indicadas en la tabla precedente. Debe tenerse en cuenta que las arenas, cuanto más finas, producen mayores grietas de contracción de fraguado y que las arenas gruesas ocasionan mayores porcentajes de rebote (ver sección 3.6.7)

Para espesores de gunitado de más de $5 \mathrm{~cm}$ y cuando se disponga de equipo adecuado, puede ser conveniente el empleo de agregados gruesos, que deberán cumplir la norma A.S.T.M. C 33 y alguna de las granulometrías de la tabla 202 (b).

Las partículas de gran tamaño deben separarse mediante cribado, para evitar obstrucciones en la manguera.

Los agregados ligeros deben ajustarse a la norma A.S.T.M. C 330 , «pecifications for Lightweight Aggregates for Structural Concrete" o a la C 332, "Specifications for Lightweight Aggregates for Insulating Concrete».

* Equivalente al tipo SF-25 del Pliego español.

** Designado como P-450 en nuestro Pliego de Condiciones.
TABLA 202 (b). Granulometrías para áridos gruesos.

\begin{tabular}{|c|c|c|c|c|}
\hline \multicolumn{2}{|c|}{$\begin{array}{l}\text { Tamiz Standard, malla } \\
\text { cuadrada }\end{array}$} & \multicolumn{3}{|c|}{$\%$ en peso que pasa por càda tamaño } \\
\hline U.S.A. & $(\mathrm{mm})$ & $\begin{array}{l}\text { Del núm. } 8 \\
\text { al } 3 / 8^{\prime}\end{array}$ & Del núm.; 4 & Del núm. 4 \\
\hline $1^{\prime \prime}$ & 25,40 & - & - & 100 \\
\hline $3 / 4 "$ & 19,05 & - & 100 & $90-100$ \\
\hline $1 / 2 "$ & 12,70 & 100 & $90-100$ & - \\
\hline $3 / 8^{\prime \prime}$ & 9,52 & $85-100$ & $40-70$ & $20-55$ \\
\hline Núm. 4 & 4,76 & $10-30$ & $0-15$ & $0-10$ \\
\hline Núm. 8 & 2,38 & $0-10$ & $0-5$ & $0-5$ \\
\hline Núm. 16 & 1,19 & $0-5$ & - & - \\
\hline
\end{tabular}

\subsubsection{Agua}

El agua para la mezcla y el curado de la gunita debe ser limpia y no contener sustancias perjudiciales para el hormigón o el acero. Cuando el acabado de la obra sea importante, el agua de curado debe estar libre de elementos que dejen manchas superficiales.

\subsubsection{Aditivos}

Es aconsejable el empleo de aditivos en el caso de calidades o condiciones de aplicación especiales. Los aditivos deben cumplir con los requerimientos de las normas A.S.T.M. C 494 "Tentative Specifications for Chemical Admixtures for Concrete", A.S.T.M. C 260, "Specifications for Air Entraining Admixtures for Concrete», A.S.T.M. C 350 , a Specifications for Fly. Ash for Use as an Admixture in Portland Cement Concrete" y A.S.T.M. C 402, "Specifications for Raw or Calcined Natural Pozzolans for Use as Admixtures in Portland Cement Concrete", en lo que tengan de aplicables *. A pesar de lo anterior, los aditivos de empleo usual en los hormigones ordinarios pueden no ser adecuados para la gunita.

- Los aditivos para la gunita pueden agruparse como sigue:

1. Acelerantes de fraguado. Cuando se requiera un fra guado rápido, y grandes resistencias iniciales, se puede utilizar cloruro cálcico u otros aditivos ecelerantes, con las debidas precauciones. La proporción de cloruro cálcico, agregado con este objeto, no debe sobrepasar el $2 \%$ en peso de la cantidad de cemento; excepto cuando se precise un endurecimiento muy rápido de la gunita como en los casos de taponamiento de filtraciones.

Los aditivos que contengan cloruro de calcio no deben usarse en la gunita en contacto con el agua de mar, o aguas con sulfatos, ni cuando la gunita haya de estar en contacto con acero pretensado o recubra dos metales distintos (aluminio y acero, por ejemplo), que estén en contacto entre sí.

2. Aireantes. Aunque no es posible ocluir aire en la gunita ejecutada por vía seca, sí pueden usarse aireantes en la gunita realizada por vía húmeda. No hay

\footnotetext{
- No existen prescripciones oficiales españolas que puedan considerarse
} aplicables a estos casos. 
datos exactos sobre los efectos en la gunita, del aire ocluido, aunque puede estimarse que aumentan su resistencia al hielo-deshielo y la manejabilidad de la mezcla. Para conseguir un cierto porcentaje de aire ocluido será necesario ocluir aproximadamente el doble de este porcentaje en la mezcla inicial, con objeto de hacer frente a las pérdidas ocasionadas en el proceso de lanzamiento.

3. Retardadores y reductores de agua. En tiempo cálido y cuando hay que dar un acabado superficial, conviene añadir un retardador de fraguado a la mezcla. También en el proceso por vía húmeda, los reductores de agua ayudan a la operación de gunitado y mejoran la calidad del hormigón.

4. Aditivos minerales. Las cenizas volantes aumentan en algunos casos la plasticidad de las mezclas y reducen su tendencia a descolgar. Las fibras de asbesto, la arcilla y otros materiales pueden también ayudar a la plasticidad, aunque deben utilizarse con cuidado puesto que aumentan la demanda de agua; con los consiguientes peligros de mayores retracciones y decrecimiento de la resistencia y durabilidad.

Los aditivos solubles deben mezclarse con agua antes de introducirlos en la mezcla. En los procesos de mezcla en húmedo, los aditivos se mezclan durante el batido de acuerdo con la práctica normal en los hormigones. En los procesos de mezcla en seco, los aditivos se añaden y baten con el agua de mezclado, que se bombea a la boquilla de salida.

\subsection{ENSAYOS PREVIOS}

\subsubsection{Generalidades}

La dosificación, la granulometría y clase de los áridos, la cuantía y espaciamiento de la armadura, el lugar de trabajo, el tipo de condiciones del equipo de transporte y especialmente la experiencia del personal, influyen en la calidad del gunitado. Deben realizarse, por lo tanto, ensayos de laboratorio antes del comienzo de la obra, para comprobar el buen funcionamiento del equipo y la calificación del personal, y prever de esta manera la calidad de gunita que se va a obtener.

\subsubsection{Ensayos previos}

Las muestras de laboratorio deben hacerse por el mismo personal que va a usar el equipo, y con los materiales y dosificaciones previstos para la obra.

En el proceso de mezcla en seco, la cantidad de agua añadida en la boquilla se regula de modo que la gunita tenga un grado adecuado de compactación, y no descuelgue ni se produzcan excesivos rebotes. Cuando la categoría e importancia de trabajo lo justifique, o no se conozcan las propiedades de los materiales que van a emplearse. es recomendable ensayar dos o tres mezclas (generalmente dentro de los límites de una parte de cemento por tres a cuatro y media partes de arena\}, antes de decidir la dosificación definitiva.

El proceso seguido en el sistema de mezcla en húmedo es similar, exceptuando que toda la mezcla se preamasa para obtener la consistencia apropiada para la obra (normalmente entre 0 y $10 \mathrm{~cm}$ de asentamiento), antes de introducirla en la cámara del equipo de impulsión. Se recomienda el hacer ensayos con más de una mezcla cuando se vayan a utilizar áridos gruesos; probando primero del 20 al $40 \%$ de árido grueso del total de la dosificación y ajustando la mezcla de acuerdo con los resultados de este primer intento.

Anteriormente se utilizaban probetas cilindricas de $6 \times 12$ " $(15 \times 30 \mathrm{~cm})$, ejecutadas proyectando la mezcla dentro de un molde de chapa metálica. Sin embargo, el Comité ha llegado a la conclusión, después de revisar cuidadosamente los factores que influyen en la calidad de la gunita y de estudiar gran cantidad de resultados de ensayos, que tales probetas no son representativas del gunitado real; especialmente en las aplicaciones en vertical y en el intradós de bóvedas o cielorrasos. No se puede confiar, por tanto, en los resultados de estos ensayos.

Aunque la determinación más segura de la calidad de la gunita se obtiene tomando una muestra de la propia estructura, esto resulta generalmente costoso y suele ser impracticable o no recomendable. Para estos ensayos previos se utilizan, por lo tanto, paneles gunitados, en los que se simulan las condiciones de trabajo reales; obteniéndose así una indicación suficientemente representativa de la calidad que se va a obtener en obra. Estos paneles se fabrican gunitando sobre un contrachapado de madera. Siendo aconsejable disponer de un panel para cada mezcla considerada, y también para cada posición de gunitado que vaya a encontrarse en obra (losas verticales, cielorrasos; etc.). Por lo menos una parte del panel debe contener la misma armadura que se piensa colocar en obra, a fin de mostrar la calidad conseguida en el gunitado detrás de la armadura. El panel debe ser suficientemente grande para obtener todas las probetas que se necesiten y para indicar la calidad y uniformidad que se pueden esperar en obra. Generalmente, no deben de ser menores de $30 \times 30^{\prime \prime} .(76 \times 76 \mathrm{~cm})$. El espesor del ensayo debe de ser el mismo de la obra, pero no inferior a 3 " $(7,6 \mathrm{~cm})$

Para realizar los ensayos se extraen, de estos paneles, cubos o cilindros. Los cilindros tendrán como mínimo un diámetro de $3 "(7,6 \mathrm{~cm})$, y la relación longitud-diámetro, L/D, será al menos, siempre que sea posible, de 1 . Las probetas se someten a ensayos de compresión a 7 y/o 28 días. Las resistencias obtenidas en los cilindros se corregirán según sea la relación $L / D$, como describe la norma A.S.T.M. C 42, "Obtención y ensayo de cilindros extraídos con trépano y cubos serrados de hormigón. Las resistencias de los cubos se pueden dar tal como se determinan, o convertidas en resistencias cilíndricas $(L / D=2)$ multiplicando por el factor $0,85^{*}$.

Las superficies cortadas de las probetas deben de ser examinadas cuidadosamente, procediéndose a cortar otras si el material no es compacto y uniforme. Todas las super-

- Para la ejecución e interpretación de estos ensayos, pueden consul-
tarse con carácter orientativo los capítulos II y IV de la Instrucción tarse con carácter orientativo los capítulos 11 y. IV de la 
ficies deben ser compactas y libres de laminaciones y bolsas de arena.

Los ensayos de absorción, resistencia al hielo-deshielo, y otras propiedades se pueden realizar, también, utilizando probetas extraídas con trépano o serradas del panel.

Los ensayos descritos más arriba, que tienen por objeto demostrar que el contratista es capaz de aplicar gunita de la calidad exigida antes de comenzar la obra, pueden retrasar en algunos casos su comienzo. Se puede por ello admitir la confección de los paneles de ensayo al mismo tiempo que se comienza el gunitado, o bien extraer muestras de la propia obra al iniciarse la colocación de la gunita. En obras relativamente pequeñas y cuando los materiales, dosificaciones, equipo y personal han dado resultados satisfactorios en trabajos precedentes, pueden no estar justificados estos ensayos.

\subsection{CARACTERISTICAS DEL EQUIPO}

\subsubsection{Proceso de mezcla en seco}

\section{a) Equipo de dosificación y mezcla.}

Se recomienda preferentemente la dosificación por peso. El cemento se puede medir por sacos completos de $50 \mathrm{~kg}$, y la arena por volumen, siempre que se hagan pesadas periódicas para asegurarse de que su peso se mantiene dentro de las tolerancias admitidas.

La humedad de la arena debe ser tal que la mezcla arenacemento fluya uniformemente (sin formar grumos), a través de la manguera. El contenido de humedad óptimo depende del equipo utilizado, pero varía generalmente entre el 3 y al $6 \%$. La arena debe secarse hasta alcanzar el nivel de humedad satisfactorio, evitando las fluctuaciones del mismo.

El equipo mezclador debe unir íntimamente la arena y el cemento (las partículas de arena deberán quedar totalmente recubiertas de cemento), y tener una producción suficiente para mantener la continuidad de la producción. El tiempo de amasado no será inferior a un minuto para mezcladoras de tambor. Cuando se empleen otros tipos de mezcladoras se debe comprobar que realizan la mezcla correctamente. La mezcladora debe ser autolimpiante y descargar todo el material sin dejar restos de una amasada para la siguiente, debiendo inspeccionarse y limpiarse completamente al menos una vez al día (o más a menudo si es necesario), para evitar que fragüen los restos de material.

\section{b) Equipo de transporte.}

El equipo de transporte será de características y dimensiones ya comprobadas por sus buenos resultados en trabajos similares. Debe permitir un control exacto de la descarga de la mezcla arena-cemento en la manguera transportadora y suministrar una corriente continua $y$ fluida de material uniformemente mezclado y a la velocidad adecuada, hacia la boquilla de descarga.
La boquilla de descarga debe estar equipada con un sistema de inyección de agua de operación manual (anillo de agua), que la distribuya uniformemente en el interior de la mezcla arena-cemento. La válvula del agua debe permitir ajustar el caudal de salida y ser de fácil manejo.

La boquilla debe suministrar un chorro cónico de gunita de apariencia uniforme en su contorno. La distorsión de esta corriente 0 cualquier apariencia de falta de uniformidad, indican que la boquilla está desgastada o que funciona mal el sistema inyector de agua.

Se debe limpiar cuidadosamente todo el equipo al final de cada turno de trabajo. Ciertas partes del mismo, especialmente la boquilla y el anillo inyector de agua, se deben inspeccionar regularmente por si precisan ser renovadas.

\section{c) Suministro de aire.}

Es necesario disponer de un compresor apropiado y de capacidad suficiente para que la operación de gunitado se realice satisfactoriamente. El compresor debe mantener un suministro de aire, limpio y seco, adecuado para proporcionar suficiente velocidad a la masa que sale de la boquilla hacia cualquier punto del trabajo y que; a la vez, sea capaz de suministrar aire al tubo utilizado para limpiar el rebote. Las capacidades de compresores indicadas en la tabla 401 (c) son las adecuadas para trabajos normales de gunitado.

La presión de trabajo es la necesaria para conducir el material desde el equipo de mezclado, a través de la manguera hasta la boquilla, y se mide mediante un manómetro próximo a la boca de salida del material. La presión del aire debe ser uniforme y constante (sin pulsaciones).

Los valores de la tabla 401 (c) se basan en una longitud de manguera de $150 \mathrm{ft}$. $(47 \mathrm{~m})$, con la boquilla a menos. de $25 \mathrm{ft}$. $(7,5 \mathrm{~m})$ por encima del equipo de gunitado. Las presiones de trabajo se aumentan generalmente en unos $0,35 \mathrm{kp} / \mathrm{cm}^{2}$ por cada $15 \mathrm{~m}$ más de manguera, y en $0,35 \mathrm{kp} / \mathrm{cm}^{2}$ por cada $7,5 \mathrm{~m}$ más de altura que se sitúe la boquilla por encima del equipo.

TABLA 401 (c). Capacidad del compresor para condiciones de operación normales.

\begin{tabular}{|c|c|c|c|c|c|c|c|}
\hline \multicolumn{2}{|c|}{ Capacidad en } & \multicolumn{2}{|c|}{$\begin{array}{l}\text { Diámetro de } \\
\text { la manguera }\end{array}$} & \multicolumn{2}{|c|}{$\begin{array}{c}\text { Diámetro } \\
\text { máximo de la } \\
\text { boquilla }\end{array}$} & \multicolumn{2}{|c|}{$\begin{array}{l}\text { Presión } \\
\text { de trabajo } \\
\text { del aire }\end{array}$} \\
\hline $\begin{array}{c}\text { cu.ft. } \\
\text { per.min. }\end{array}$ & $\mathbf{m}^{3} / \mathbf{h}$ & (in.) & $(\mathrm{cm})$ & (in.) & (cm) & (psi) & $\left(\mathrm{kp} / \mathrm{cm}^{2}\right)$ \\
\hline 250 & 425 & 1 & 2,5 & $3 / 4$ & 1,9 & 40 & 2,8 \\
\hline 315 & 535 & $11 / 4$ & 3,2 & 1 & 2,5 & 45 & 3,2 \\
\hline 365 & 620 & $11 / 2$ & 3,8 & $11 / 4$ & 3,2 & 55 & 3,9 \\
\hline 500 & 850 & $15 / 8$ & 4,1 & $11 / 2$ & 3,8 & 65 & 4,6 \\
\hline 600 & 1.020 & $13 / 4$ & 4,4 & $15 / 8$ & 4,1 & 75 & 5,3 \\
\hline 750 & 1.275 & 2 & 5,1 & $13 / 4$ & 4,4 & 85 & 6,0 \\
\hline
\end{tabular}

\section{d) Suministro de agua.}

La presión del agua en la boquilla de descarga debe de ser mucha mayor que la del aire, para asegurar su salida y una mezcla perfecta con los otros materiales. Si la 
presión de agua en la línea de suministro es insuficiente debe intercalarse una bomba. Del mismo modo que para el suministro del aire, la presión del agua debe de ser constante y uniforme.

\section{o) Equipos de mezcla en seco.}

Se han recibido algunos informes alentadores, procedentes del exterior de los Estados Unidos, sobre el gunitado de mezcla en seco con áridos hasta de $25 \mathrm{~mm}$, que indican que esta clase de trabajo es posible. Sin embargo, como no hay suficiente información sobre la puesta en obra, el rendimiento del equipo y los resultados obtenidos no se puede, por el momento, recomendar su uso con carácter general. Esta mezcla tiene la ventaja del menor contenido de cemento y agua, en el caso de secciones de espesores fuertes. Sin embargo, la capacidad del equipo de mezclado para áridos gruesos y la efectividad de la unión del agua, añadida en la boquilla, con los otros ingredientes deben investigarse aún más. Por otra parte, la adición de áridos gruesos a la mezcla provoca un aumento de rebote que, a su vez, también aumenta el contenido de cemento y las pérdidas de material, haciendo más difícil el realizar un gunitado correcto en secciones armadas.

\subsubsection{Proceso de mezcla húmeda}

\section{a) Equipo de dosificación y mezclado.}

Se prefiere y recomienda fuertemente, la dosificación en peso. El cemento, en lugar de pesarse, puede ser em pleado en sacos enteros de $50 \mathrm{~kg}$. Los áridos pueden dosificarse por volumen sí se realizan comprobaciones periódicas de su peso específico aparente, para asegurarse que se mantiene dentro de las tolerancias admitidas. El agua puede dosificarse por peso o por volumen.

El equipo mezclador debe ser capaz de mezclar completamente los materiales, en cantidad suficiente para mantener una puesta en obra continua. El tiempo necesario para el mezclado depende del tipo de mezcla y de la eficiencia de la hormigonera; la masa debe cumplir las prescripciones de la norma A.C.I. 614, "Recomendaciones prácticas para medir, mezclar y colocar hormigones". Cuando se utiliza hormigón prefabricado, se debe seguir la norma A.S.T.M. C 94, «Especificaciones para hormigones prefabricados". El empleo de hormigón de la compacidad prevista y de calidad uniforme es fundamental para una buena operación de gunitado, especialmente en paramentos verticales y en cielorrasos *.

\section{b) Equipo.}

Los equipos de alimentación neumática para mezclas húmedas son apropiados para aplicar mortero u hormigón de buena calidad y pequeños asientos, en construcciones y reparaciones de tipo general. En estos equipos, un recipiente sometido a presión descarga los materiales premezclados y el aire comprimido a la manguera. El material y el aire pasan de la manguera en la boquilla de gunitado, la que está provista de un anillo inyector de aire, que puede suministrar aire comprimido ádicional.

- Véase el capítulo III, Ejecución, de la instrucción española (1968).
Recientemente se ha introducido en el mercado un tipo de equipo para transportar mezcla húmeda por medio de impulsos. En este caso, el mortero premezclado o el hormigón se impulsa hacia la manguera mediante una bomba de pistón u otro sistema no neumático. Cuando se utiliza para gunitado, se añade una boquilla, al final de la manguera, que va equipada con un anillo que inyecta aire comprimido dentro del flujo de material.

Algunos datos existentes indican que los asientos son, en este caso, generalmente más altos, la velocidad de impacto menor y la longitud de la manguera no puede ser tan larga como con los equipos de alimentación neumática. Sin embargo, se ha demostrado que con algunos de estos equipos se obtiene gunita de buena calidad para muchas aplicaciones, particularmente para el caso de losas y planos inclinados. El Comité tiene todavía algunas reservas acerca de que con este sistema se pueda lograr un buen gunitado en paramentos verticales y en techos. Cuando se vaya a utilizar, es absolutamente necesario realizar ensayos previos (ver capítulo 3.3) para comprobar que puede conseguirse la calidad deseada, con el equipo y métodos propuestos.

El equipo para mezcla húmeda debe tener las características y dimensiones que hayan proporcionado resultados satisfactorios en obras similares. Debe desde luego suministrar los materiales premezclados exacta, uniforme y continuamente a través de la manguera de transporte. El diámetro de la manguera varía de $111 / 4$ a $21 / 2$ " (32 y $64 \mathrm{~mm}$ ). Deben seguirse las recomendaciones del fabricante para seleccionar el tipo y tamaño de la boquilla, y para la limpieza, inspección y mantenimiento del equipo.

\section{c) Suministro de aire.}

El compresor debe mantener un suministro de aire suficiente para obtener la velocidad requerida en la boquilla y en cualquier parte de la obra, así como proporcionar, simultáneamente, aire a la tubería de separación del rebote. No se dispone de datos suficientes para recomendar la capacidad del compresor necesario, ni la presión de operación correcta.

\subsection{CALIDAD Y OBLIGACIONES DE LA MANO DE OBRA}

\subsubsection{Calidad de la mano de obra}

La bondad del gunitado depende en gran parte de la experiencia de la mano de obra empleada, del mismo modo que la clase de una soldadura depende de la habilidad del soldador. El encargado, el operador de la boquilla, y el que tiene a su cargo el equipo mezclador e impulsor, deben demostrar que han realizado trabajos satisfactorios de importancia similar en obras parecidas, durante un período suficiente, antes de calificarse, como capaces de llevar a cabo sus obligaciones satisfactoriamente.

El encargado debe tener una gran experiencia personal, preferentemente en el manejo de la boquilla (al menos de dos años). 
El operario que maneja la boquilla debe de haber tenido por lo menos seis meses de aprendizaje en operaciones similares y demostrará, mediante pruebas, su capacidad para realizar satisfactoriamente el trabajo, y para llevar a cabo gunitados de la calidad requerida.

En el capítulo 3.3 se describen los ensayos adecuados para el control y calificación previa del personal.

\subsubsection{Obligaciones}

Las obligaciones del operador de la boquilla son:

1. Asegurarse que toda la superficie a gunitar está limpia y libre de lechada o materiales sueltos utilizando si es necesario, chorro de aire o de agua-aire, con el mismo equipo de gunitado.

2. Asegurarse de que la presión de aire es uniforme y proporciona velocidad suficiente para la compactación adecuada del material.

3. Regular el contenido de agua de tal forma que la mezcla sea suficientemente plástica para una buena compactación con bajo porcentaje de rebote, pero lo más seca posible para que no se desprenda. (En el proceso de mezcla en seco, el operario de la boquilla controla el agua de amasado, mientras que en el proceso de mezcla en húmedo exige los cambios de consistencia requeridos para un buen trabajo.)

4. Mantener la boquilla a la distancia apropiada y tan perpendicular a la superficie como lo permita el tipo de trabajo, con objeto de asegurar la máxima compactación y el mínimo rebote.

5. Seguir una secuencia de trabajo rutinaria, de forma que se llenen todos los rincones mediante un gunitado uniforme y queden envueltas las armaduras sin huecos detrás de las mismas, empleando capas de gunita del máximo espesor posible.

6. Decidir el sistema de trabajo adecuado para el gunitado de lugares estrechos a larga distancia o alrededor de obstáculos extraños, coordinando para ello la velocidad de colocación y la consistencia de la mezcla.

7. Advertir al personal correspondiente cuándo debe empezar y cuándo detener el suministro de material, interrumpiendo el gunitado cuando el material no llegue con uniformidad a la boquilla.

8. Asegurarse de que se detectan las bolsas de arena o aire y que son destruidas y separadas posteriormente.

9. Hacer el gunitado en forma limpia y progresando uniformemente.

El operador del equipo de transporte debe manejar el alimentador mecánico y dirigir el trabajo del personal de mezclado; recibiendo instrucciones o señales del operario de la boquilla para suministrar el material requerido. Su misión más importante es comprobar que el flujo de material hacia la boquilla es uniforme y a la presión requerida por el operador de la boquilla. También es de su responsabilidad asegurarse que no se envía a la boquilla material que tenga más de 45 minutos de haberse mezclado.
El aprendiz de operador de la boquilla, o ayudante, manejará una tubería soplante de $19 \mathrm{~mm}$ (3/4") de diámetro como mínimo, para ayudar al operador de la boquilla, separando todo el rebote o cualquier otro material poroso o suelto, perjudicial a la capa de gunitado (excepto en los tipos de trabajo en que el rebote puede ser eliminado por el operador de la boquilla). También ayudará al operador en otras tareas si lo requiere para ello.

Otro ayudante del operador de la boquilla es el encargado de la manguera. Ayuda al arrastre de ésta manteniéndola en posición correcta para facilitar la progresión del trabajo. En algunas obras, el ayudante del operador también se encarga de la manguera. La figura 33 muestra a un operador de la boquilla, un operario de manguera y un ayudante, gunitando un tejado.

\subsection{ESPECIFICACIONES DE TRABAJO}

\subsubsection{Generalidades}

Cualquier gunitado debe describirse completamente mediante dibujos y especificaciones, que estarán a disposición del supervisor y ejecutores de la obra antes de su comienzo.

\subsubsection{Preparación de las superficies que van a gunitarse}

Cuando la gunita se proyecte directamente sobre el terreno, como en el caso de revestimiento de canales, los paramentos deben previamente compactarse, rectificándose las alineaciones y pendientes. La gunita no se debe colocar sobre superficies heladas, esponjosas o que rezumen agua, aunque deben conservarse húmedas desde varias horas antes.

En caso de reparaciones de hormigón deteriorado, es esencial la eliminación previa de todo el material poco firme. Deben picarse hasta el fondo las cavidades o nidos de grava, de forma que no se produzcan cambios bruscos en el espesor de la reparación. No deben dejarse esquinas agudas en el contorno de las cavidades, repasando sus bordes adecuadamente. La capa superficial final debe examinarse cuidadosamente, asegurándose de que son correctas su forma y solidez. Las deficiencias en la preparación de las superficies que van a repararse son, en la mayoría de los casos, la causa de los fallos de gunitado. La figura 32 muestra la preparación de una superficie que va a repararse.

Después de sanear cuidadosamente la superficie del hormigón, mampostería, o acero que vaya a gunitarse, se limpiará mediante chorro de arena. Inmediatamente antes del gunitado, todas las superficies se limpiarán cuidadosamente, y las de hormígón y mampostería se regarán.

En la práctica, el operador que maneja la boquilla proyecta sobre las superficies un chorro de agua-aire, secando a continuación mediante aire sólo. Las superficies porosas deben mantenerse mojadas varias horas antes del qunitado. 


\subsubsection{Encofrados}

Los encofrados deben ser de contrachapado, madera u otro material que permita obtener alineaciones y medidas correctas, y deben arriostrarse de modo que no vibren excesivamente. Se construirán de manera que dejen escapar el aire y el rebote; lo que es de gran importancia en caso de elementos estructurales gruesos. (Véase el apartado 3.6.10.)

En las intersecciones deben colocarse pequeños mamparos desmontables. Los encofrados se tratarán con un desencofrante adecuado, limpiándose antes de comenzar el gunitado.

Debe preverse un andamiaje que permita al gunitador sostener la boquilla, frente a toda la superficie con el ángulo y distancia correctos, definidos en el apartado 3.6.6. El andamio permitirá también un acceso fácil a la superficie en los casos en que ésta deba fratasarse o ser objeto de otro tipo de acabado.

Los andamios, siempre que sea posible, se construirán de modo que no haya que interrumpir el trabajo.

\subsubsection{Armaduras}

Es muy importante, para obtener una gunita de buena calidad, que el proyecto y la colocación de las armaduras se haga de manera que ocasionen el menor estorbo posible a la operación de gunitado. Dependiendo del espesor de la capa de gunita y de la clase de trabajo, la armadura puede consistir en barras de sección circular o en una malla de alambres unidos mediante soldadura. (Se puede suprimir el armado en el caso de pequeñas reparaciones.) Las barras para el armado deben ser delgadas, siendo las del número 5 las más gruesas, excepto en casos excepcionales en los que hay que tomar las precauciones necesarias para que queden perfectamente envueltas por la gunita.

Hay que prever suficiente espacio alrededor de las armaduras para que queden completamente envueltas con la gunita. (En el caso de depósitos pretensados y en otras aplicáciones especiales, la armadura se aplica directamente sobre la superficie del hormigón, y son necesarias mezclas y técnicas de colocación especiales para conseguir un buen recubrimiento.) El espacio libre alrededor de la armadura depende naturalmente del tamaño máximo del árido y de su diámetro. El mínimo espacio que debe quedar entre las barras y el encofrado, o el material de soporte, variará entre $1 / 2$ " (13 $\mathrm{mm}$ ), para el caso de proyectarse mezcla de mortero, y consistir la armadura en un mallazo, y $2 "(50 \mathrm{~mm})$, cuando se trate de hormigón proyectado y armaduras del número 5 . El recubrimiento mínimo debe cumplir, además, el Pliego de Condiciones de la obra, y las Normas Oficiales aplicables. El espaciamiento mínimo de los alambres, en el caso de mallas soldadas, deberá ser de $2 \times 2 "(5 \times 5 \mathrm{~cm})$. La separación mínima entre barras paralelas deberá ser de $21 / 2 "(6,4 \mathrm{~cm})$. Siempre que sea posible se colocarán las armaduras de tal modo que permitan gunitar su parte posterior desde ambos lados, formando para ello el eje del chorro un pequeño ángulo con la normal a la superficie.

Los solapes, tanto de las mallas como de las armaduras, deben estudiarse con cuidado para evitar que ocasionen secciones de gunitado débiles. En el solape, las armaduras no deben atarse juntas, sino dejando entre ellas una separación de 2" (50 mm) como mínimo, siempre que sea posible. Las mallas deben solaparse un cuadro y medio en todas las direcciones. Los dispositivos para mantener la separación entre las armaduras y la superficie que se va a gunitar no deben colocarse debajo de las barras, con objeto de evitar que se formen bolsas de arena detrás de las misma (fig. 34).

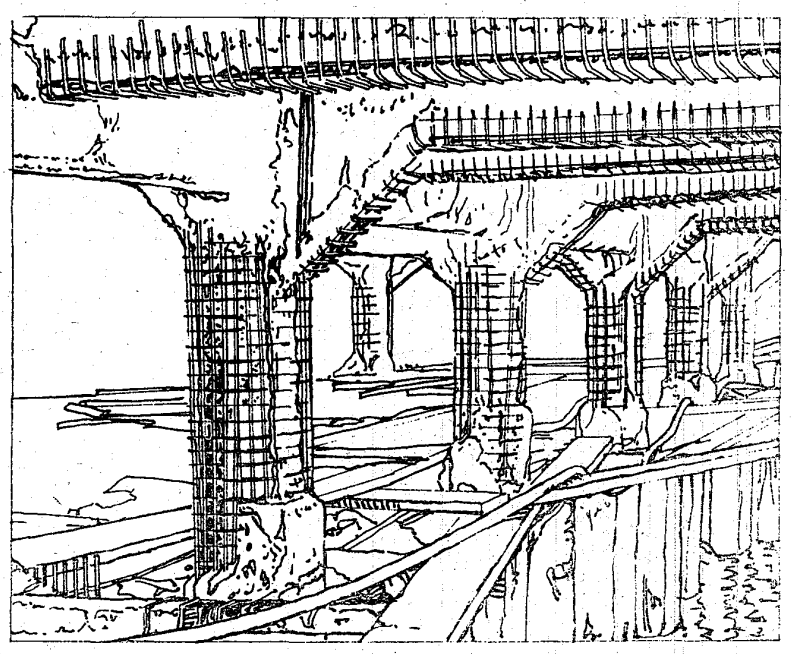

Fig. 32.Reparación mediante gunita de una estructura de muelle marino.

Las armaduras se asegurarán firmemente en la posición indicada en los planos.

Todas las armaduras deben estar libres de escamas de laminación, oxidaciones, aceites y cualesquiera otros productos que puedan ser obstáculo para una buena adherencia a la gunita.

\subsubsection{Control de alineaciones}

Deben colocarse alambres, anclados en el suelo, que sirvan de guía para obtener los espesores y superficies de gunitado que se deseen.

Los alambres, verticales y horizontales, servirán de referencia para las esquinas y entrantes que no queden marcados claramente por los encofrados (aristas exteriores de los muros, pilares y vigas de esquina, etc.).

Estas referencias pueden también servir de guía para los fratasados. Se recomienda para estos usos el alambre de piano de calibre 18 ó 20. Estos alambres de referencia deben quedar fuertemente sujetos y colocados de manera que permitan su tensado posterior.

\subsubsection{Gunitado}

Cada una de las capas de gunitado se ejecutará mediante varios pases de la boquilla sobre el área de trabajo. La 
gunita debe salir de la boquilla con un flujo uniforme e. ininterrumpido. Si el flujo se hace intermitente por cualquier causa, el operador debe dirigir el chorro a lugar distinto del de trabajo, hasta que, de nuevo, se obtenga la uniformidad.

La distancia de la boquilla a la superficie que se gunite debe oscilar entre 2' y 5' (60 a $150 \mathrm{~cm})$, adaptándola en cada caso a las condiciones de trabajo. Como regla general la boquilla debe mantenerse perpendicular a la superficie de aplicación. Sin embargo, cuando la proyección se hace a través de armaduras, la boquilla se sitúa más próxima y formando un pequeño ángulo con la perpendicular para que las armaduras queden mejor recubiertas y para facilitar la extracción del rebote. También la mezcla debe ser en este caso algo más fluida que la normal, aunque no tanto que se descuelgue en la parte posterior de las armaduras. Este procedimiento fuerza a la gunita, más plástica, a penetrar detrás de las barras e impide, a la vez, el regruesamiento de material en la parte frontal de las mismas, como indica la figura 10. Cuando las barras están muy próximas, se pueden gunitar varias de ellas desde cada posición lateral.

En el gunitado de muros la aplicación debe comenzarse por la parte inferior. La primera capa de gunita ha de tapar completamente la armadura más próxima al encofrado. Los espesores de cada capa de gunita deberán ser lo mayores posible, siempre que la gunita no se descuelgue fresca por su propio peso. Cuando se aplica la gunita en capas gruesas, es importante que la inclinación del borde superior sea de $45^{\circ}$ aproximadamente, y que el rebote pueda quitarse sin interferir en el trabajo de proyección. En el gunitado de losas la boquilla se mantendrá formando un pequeño ángulo con la perpendicular a la losa para lograr que el rebote se proyecte sobre la zona ya terminada y sea más fácil su eliminación.

La figura 35 muestra las operaciones de gunitado y aca. bado superficial de un tejado.

\subsubsection{Rebote}

El rebote está constituido por los áridos y pasta de cemento que, debido al choque con la superficie que se gunita, con las armaduras o con los propios áridos, se desprende de la zona de trabajo. La cantidad de rebote producida es función: de la inclinación de la superficie, de la presión de trabajo del aire, de las cantidades de cemento y de agua, del árido de mayor tamaño, de su granulometría, de la cuantía de las armaduras y del grueso de la capa de gunitado. Sus valores aproximados son:

\begin{tabular}{l|c}
\hline \multicolumn{1}{c|}{ Tipo de superficie } & $\begin{array}{c}\text { Porcentaje de rebote } \\
(\%)\end{array}$ \\
\hline Pisos o losas & 5 al 15 \\
Muros verticales o inclinados & 15 al 30 \\
Techos & 25 al 50 \\
\hline
\end{tabular}

Al iniciar el trabajo, el porcentaje de rebote es grande y decrece a medida que la propia gunita forma como un cojín plástico, al que se dirige el chorro.

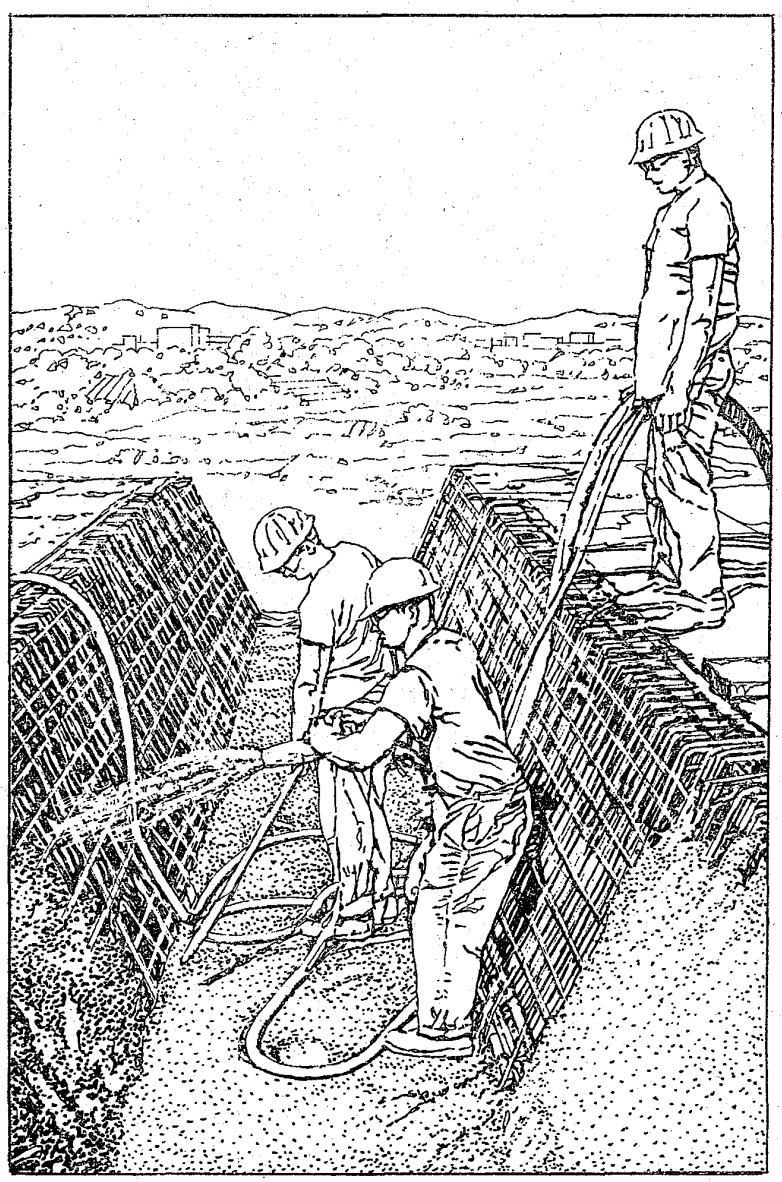

Fig. 33. Equipo de gunitado.

El rebote está constituido por un mortero más pobre y con mayor contenido de agregados gruesos que el original. El contenido de cemento, de la gunita que queda adherida a la base es, por esta causa, más alto; de donde resulta, para la misma, una mayor resistencia y más retracción de fraguado.

El rebote no debe retirarse de la zona de trabajo por el operario que maneja la boquilla, aunque si no se desprende solo ha de ser separado. El rebote, una vez quitado, no debe aprovecharse para nuevos amasados, debido al peligro que varíen imprevisiblemente el contenido de cemento, la cantidad de agua y la granulometría de la mezcla.

\subsubsection{Juntas de construcción}

Las juntas de construcción, debidas a interrupciones del trabajo, se deben realizar de modo que el espesor de la última capa lanzada disminuya gradualmente en una anchura aproximada de $30 \mathrm{~cm}$ (1'). Puede hacerse también otro tipo de junta, de mejor apariencia, disminuyendo el espesor de la gunita gradualmente hasta una pleza de madera de un espesor aproximado de $2,5 \mathrm{~cm}$ (1") que 

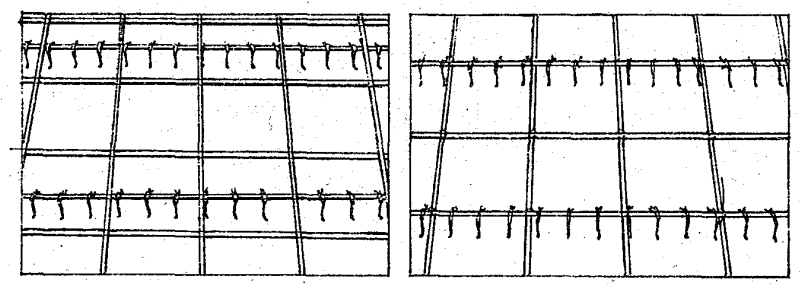

Fig. 34. Colocación correcta (izquierda) e incorrecta (derecha) de separadores de barras.

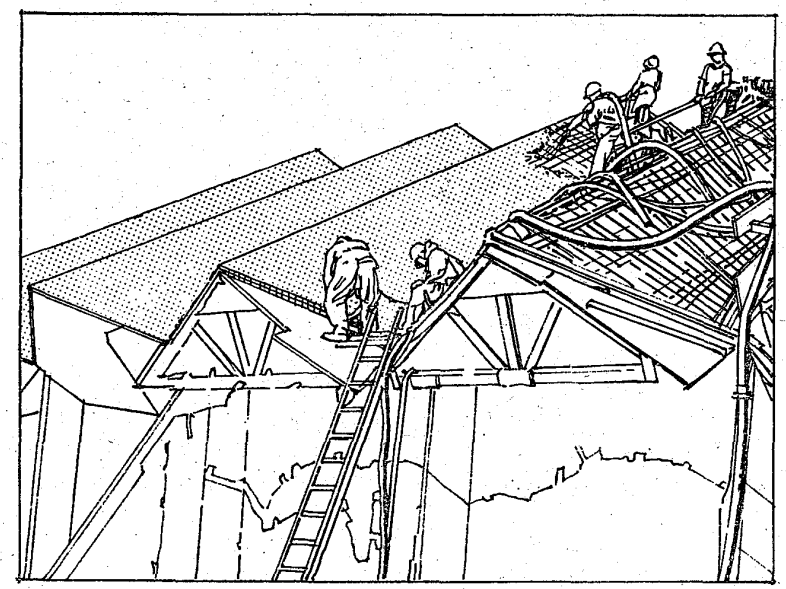

Fig. 35. Gunitado de un techo; obsérvese el gunitado en el fondo y la operación de acabado en el centro.

se fija previamente por su lado plano sobre la superficie, en el lugar de la junta (fig. 16).

Normalmente, las juntas en ángulo recto deben evitarse, puesto que dan lugar a rincones en los que puede almacenarse el rebote.

Sin embargo, cuando la junta va a quedar sometida a esfuerzos de compresión, debe hacerse en ángulo recto y tener prevista la retirada del rebote. Todas las juntas deben limpiarse cuidadosamente, así como mojarse inmediatamente antes de reanudar el trabajo.

\subsubsection{Preparación para aplicar capas sucesivas}

Para cubrir una capa de gunita con la siguiente, hay que esperar al fraguado inicial de la primera. Además; limpiarla con cepillo de todos los restos de lechada, material suelto y rebote. Si la lechada ha fraguado totalmente hay que eliminarla mediante chorro de arena, limpiando después la superficie con un martillo para localizar las zonas en las que existan cavidades, nidos de arena o falta de adherencia. Estas zonas defectuosas deben eliminarse mediante corte y separación de la gunita, que debe sustituirse por otra nueva. Todas las superficies que vayan a gunitarse deben mojarse previamente.

\subsubsection{Gunitado de partes estructurales gruesas}

Teniendo en cuenta su calidad y coste, la gunita se adapta mejor para la construcción de secciones delgadas $y / 0$ ligeramente armadas. Sin embargo, es conveniente a veces el gunitar ciertos elementos estructurales en construcciones nuevas, así como unir pilares, vigas o muros, a construcciones ya existentes.

El uso de la gunita en secciones estructurales requiere, para tener éxito, un cuidadoso proyecto, la utilización de encofrados de buena calidad, y un gran cuidado en la ejecución. El tamaño de la boquilla y la velocidad de alimentación deben reducirse lo necesario para lograr un control adecuado del trabajo y una aplicación uniforme y densa, aun en zonas estrechas y difíciles para el trabajo. Para permitir el escape de aire y el del rebote durante la operación de gunitado, en el caso de pilares, se encofrarán únicamente dos caras adyacentes, aunque pueden también obtenerse buenos resultados encofrando tres caras cuando el ancho es al menos de una y una vez y media la profundidad. En el caso de pilares, las dos caras encofradas pueden ser las adyacentes o las opuestas. En el de vigas debe encofrarse el fondo $\mathrm{y}$ una de las caras, obteniendo así la máxima área de salida para el aire y el rebote. Hay que colocar puntales debajo del encofrado de las vigas para que no lo deforme el peso de la gunita antes de su endurecimiento:

Donde la sección tenga una armadura situada en dos planos diferentes, es útil el colocar la armadura superior después de recubrir la primera con gunita. Sin embargo, pueden obtenerse buenos resultados gunitando a través de los dos planos de armadura, cuando, en la más próxima a la boquilla, el espaciamiento de las barras en las dos direcciones, sea por lo menos 12 diámetros, y en el segundo plano de armado, el espaciamiento, en ambas direcciones, sea igual o superior a 6 diámetros de las barras.

En general no se recomienda aplicar gunita en fisuras estrechas o en agujeros, que deben llenarse con hormigón o mortero convencionales colocados en seco. Estas áreas pueden después recubrirse con gunita al mismo tiempo que las contiguas. No debe usarse gunita para hormigonar pilares zunchados ni pilotes.

\subsubsection{Acabados}

El acabado natural de la gunita, desde el punto de vista estructural y el de la durabilidad, es preferible a cualquier otro obtenido mediante operaciones posteriores. Existe el peligro de que estos acabados modifiquen las secciones, perjudiquen la unión entre la armadura y la gunita, o entre la gunita y la capa adyacente, y den lugar a formación de grietas. Además, los acabados fínales pueden ser difíciles de ejecutar cuando se emplean mezclas muy secas.

Sin embargo, el acabado natural de la gunita es inaceptable para ciertas estructuras a causa de su rugosidad. Cuando se requiera una superficie más lisa o de mejor aspecto, debe recurrirse a acabados especiales. En general, cuando la gunita ha comenzado a fraguar (lo que se nota por el crujido que se produce al cortarla), el 
exceso de material que sobresale de los encofrados y de los alambres guía se corta y separa mediante una regla afilada. Se quitan después los alambres guía y se deja tal cual la superficie o bien se fratasa.

Cuando se requiere un acabado aún más fino, de mejor aspecto, se aplica una rápida capa fina (flash), que consiste en cubrir la superficie con una mezcla de arena -más fina que la normal- y cemento, que se proyecta manteniendo boquilla a mayor distancia del paramento que la usual. Este acabado debe aplicarse tan pronto como sea posible, después del repaso inicial. La operación puede completarse con alguna de las siguientes:

1. Fratasado, con llana de madera, que da una textura granular.

2. Fratasado, con llana de goma, que deja una textura final rugosa.

3. Enlucido, con llana metálica, qúe deja la superficie muy fina.

\subsubsection{Mezclas especiales}

A veces es necesario el empleo de gunita de 'características especiales como: bajo peso específico, gran capacidad aislante o resistencia mayor de la normal al calor o a los ácidos. Estas exigencias obligan a emplear áridos o cementos especiales.

Las mezclas con áridos ligeros son de uso creciente para el gunitado de paredes y suelos. La gunita con áridos ligeros es, como la normal, para secciones delgadas $y / o$ ligeramente armadas. Hay que poner especial cuidado en el proyecto y en la ejecución de esta- clase de gunitados, cuando incluyen partes estructurales.

La gunita se emplea a menudo como protección contra el fuego (fire proofing), de las estructuras metálicas, utilizando, para este uso, agregados ligeros. La gunita, así empleada, refuerza la estructura metálica, circunstancia que puede ser tenida en cuenta en su cálculo.

Cuando se desea una gunita de endurecimiento rápido o de gran resistencia al calor (apartado 3.2.1), se emplea en su confección cemento aluminoso en lugar de portland normal. Esta clase de gunita es, además, resistente a los ácidos. Para obtener recubrimientos refractarios, se usan cementos aluminosos y áridos térmicamente estables.

Los tipos de mezclas anteriores requieren procedimientos de aplicación específicos, para fijar los cuales deben tenerse en cuenta las recomendaciones de los fabricantes de cementos especiales y las de los suministradores de áridos. Cuando se presenten dificultades en el gunitado de mezclas de bajo revenimiento, conteniendo áridos ligeros, ásperos o porosos, debe preferirse el proceso de fabricación por vía seca al de vía húmeda.

\subsubsection{Interrupciones en el trabajo}

El gunitado debe suspenderse temporalmente cuando:

1. La fuerza del viento impide al operador la proyección correcta de la gunita.
2. A temperaturas próximas a $0^{\circ} \mathrm{C}$, cuando no puede protegerse el trabajo, a medida que se vaya realizando.

3. En caso de lluvia, que arrastre el cemento de la gunita fresca ocasionando desprendimientos.

\subsubsection{Curado y protección en tiempo frío}

Es particularmente importante el curado de la gunita por tratarse de secciones delgadas, en las que se emplean mezclas ásperas y de bajo revenimiento. Por todo ello se recomienda que la superficie de los gunitados se mantenga continuamente mojada por los menos durante los 7 primeros días. Los productos de curado en forma de membrana superficial no deben utilizarse en los casos de gran sequedad ambiente, cuando se va a aplicar encima un nuevo gunitado, o vaya a pintarse la superficie y en donde no resulten aceptables desde el punto de vista estético. Debido a la rugosidad de la superficie, el poder de cobertura de estos productos puede disminuir hasta la mitad del que tienen sobre paramentos de hormigón ordinarios.

El aire en contacto con la superficie de la gunita debe mantenerse a temperatura superior a $0^{\circ} \mathrm{C}$ al menos 7 dias después del gunitado. Se pueden encontrar más detalles sobre esta protección durante el invierno en la «Recommended Practice for Cold Weather Concreting (A.C.I. 306-66) ".

\subsubsection{Control de calidad}

El control de calidad de la gunita es más difícil que el de los hormigones ordinarios, puesto que influyen en el mismo no solamente la proporción de las mezclas, la calidad de los agregados y su batido, sino, en mayor grado, la destreza y el continuo cuidado durante el trabajo del equipo de aplicación.

No es deseable, ni posible, en la mayoría de los casos, el obtener muestras del trabajo para llevar un control " de calidad de forma regular. En consecuencia, se deben obtener periódicamente muestras no armadas, proyectando gunita sobre paneles de madera que tengan por la menos $30 \times 30$ y $7,5 \mathrm{~cm}$ de espesor $(1 \times 1 \mathrm{ft}$. y $3 \mathrm{in})$, de los que se cortarán cilindros 0 cubos para ensayarlos a la compresión o para su examen visual, descrito en el capítulo 3.3.

Aunque no se recomienda de modo general, algunos ingenieros han comprobado que, para determinada clase de trabajos y técnicas de colocación, da resultados satisfactorios el control diario mediante el ensayo de cilindros obtenidos gunitando sobre moldes de tela metálica.

Se recomienda emplear una malla metálica de 16 a $19 \mathrm{~mm}$ (5/8 a 3/4") para las muestras de mortero, y de $25 \mathrm{~mm}$ ( 1 ") en el caso de muestras con áridos gruesos. El exceso de material que sobresalga del molde se nivela con una espátula. A las 24 horas de obtenidos los cilindros por el procedimiento anterior, se quita la malla exterior. Cuando se obtengan estas dos clases de muestras, los resultados de las mismas deben irse comparando entre sí. 
Se recomienda sacar muestras trepanadas con la frecuencia necesaria para asegurarse de que los ensayos de control van reflejando con exactitud la calidad del material.

Los resultados de los ensayos deben ser evaluados de acuerdo con la norma A.C.I. 214-65, «Evaluation of Compressive Test Results of Fiel Concrete». Acompañando los ensayos debe ir la correspondiente documentación.

\subsubsection{Inspección}

El gunitado se someterá a una inspección permanente de persona calificada; esta inspección revisará los materiales, encofrados, armaduras, alambres de alineación, equipo, colocación del material y curado y protección contra las heladas, si ha lugar. Todas las capas de gunita deben gol- pearse con un martillo para descubrir las zonas huecas, que se repararán. Se extraerán muestras del trabajo para comprobar la calidad de la gunita ya colocada, especialmente cuando se trate de estructuras; estas muestras se obtendrán lo antes posible, con objeto de que, los datos que proporcionen, puedan tenerse en cuenta para mejorar la calidad del trabajo en el curso de su desarrollo.

\subsubsection{Protección de las superficies próximas a la zona de trabajo}

La superficie de las zonas próximas al trabajo que no vayan a ser gunitadas, se protegerán de las salpicaduras recubriéndolas con papel impermeable o por otros medios adecuados. Las estructuras próximas y los pisos que puedan dañarse con el polvo o con el rebote, deben asimismo protegerse.

\subsection{INDICE PARA EL MANEJO DE LAS NORMAS}

3. Normas para la ejecución y empleo de la gunita (Standard Practice for Shotcreting.

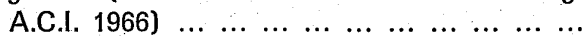

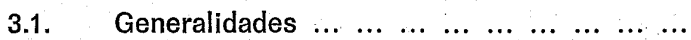

3.1.1. Introducción $\ldots \ldots \ldots \ldots \ldots$

3.1.2. Tipos de gunita $\ldots \ldots \ldots \ldots \ldots \ldots$

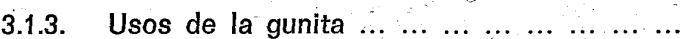

3.1.4. Propiedades de la gunita $\ldots \ldots \ldots \ldots \ldots$

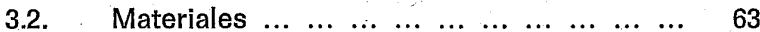

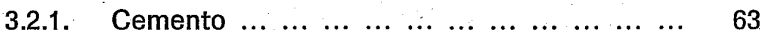

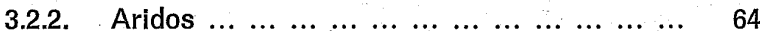

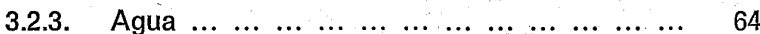

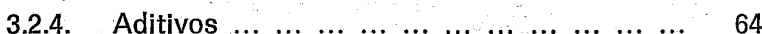

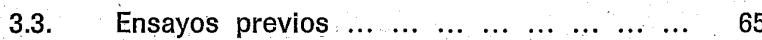

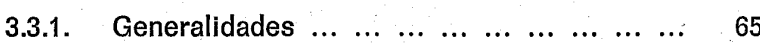

3.3.2. Ensayos previos $\ldots \begin{array}{lllllllll} & \ldots & \ldots & \ldots & \ldots & \ldots & \ldots & \ldots & 65\end{array}$

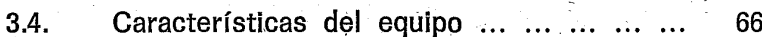

3.4.1. Proceso de mezcla en seco ... ... ........ 66

3.4.2. Proceso de mezcla húmeda $\ldots \ldots \ldots \ldots, \ldots . .67$

3.5. Calidad y obligaciones de la mano de obra.
Págs.

\section{2.}

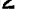

62

63

63

63

3.

4

4

4.

5

65

(1)

66

66

67

67

3.5.1. Calidad de la mano de obra ... ... ........ 67

$\begin{array}{llllllllllll}3.5 .2 & \text { Obligaciones } \ldots & \ldots & \ldots & \ldots & \ldots & \ldots & \ldots & \ldots & \ldots & \ldots & \end{array}$

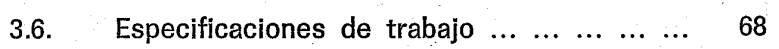

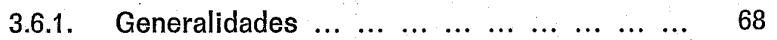

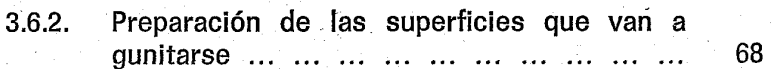

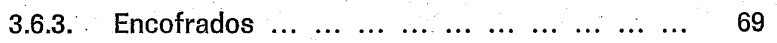

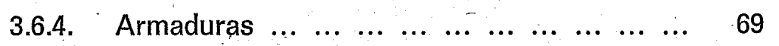

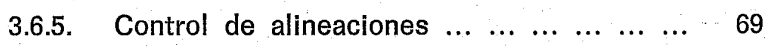

3.6.6. Gunitado $\ldots \begin{array}{llllllllllll} & \ldots & \ldots & \ldots & \ldots & \ldots & \ldots & \ldots & \ldots & \ldots & \ldots & \ldots\end{array}$

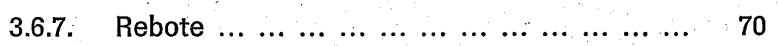

$\begin{array}{lllllllll}\text { 3.6.8. Juntas de construcción } & \ldots & \ldots & \ldots & \ldots & \ldots & \ldots & 70\end{array}$

3.6.9. Preparación para aplicar capas sucesivas ... 71

3.6.10. Gunitado de partes estructurales gruesas ... 71

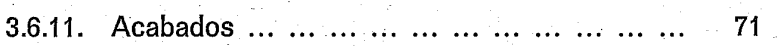

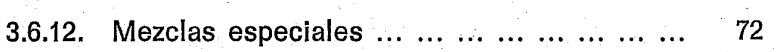

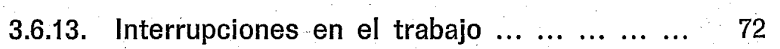

3.6.14. Curado y protección en tiempo frío ... ... 72

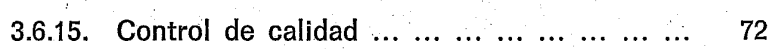

$\begin{array}{llllllllllllll}3.6 .16 . & \text { Inspección } & \ldots & \ldots & \ldots & \ldots & \ldots & \ldots & \ldots & \ldots & \ldots & \ldots & 73\end{array}$

3.6.17. Protección de las superficies próximas a la

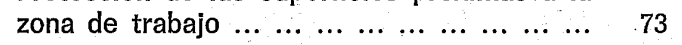




\section{\& Referencias}

"A.C.I. Standard Recommended Practice for Shotcreting". Traducción española por el Dr. Ing. C. C. C. Luis Martínez Díaz, con el título: "Normas para la ejecución y empleo de la gunitan.

"Dry - Mix Shotcrete Practice", Theodore R. Crom.

"Wet-Mix Shotcrete Practice", T. A. Hoffmeyer.

"Structural Quality Lightweith Shotcrete», Philip D. Barnard and Robert E. Tobin.

"Technologie des Spritzbetons", Richard Linder.

"Zur Technologie des Spritzbetons", O. Drögsler.

"Dry-Mix Coarse-Aggregate Shotcrete as Under ground Support", Helmut G. Kobler.

"Report on Gunite at Arrowrock Dam", Claude H. Studebaker.

"Shotcrete as a Construction Material», T. J. Reading.
"Properties or Sand-Mix Shotcrete", Stanley G. Zynda.

"Laboratory Study of Shotcrete", Albert Litvin and Joseph J. Shideler.

"Guniting as a Swimming Pool", Parker, J. L.

"Travaux d'Etanchement au Métro de Paris".

"Spritz Beton im Tunnelbau", Hans Potthast.

"The New Austrian Tunnelling Method", L. Rabcewicz.

"Betrachtungen zur Entwicklung im Tunnelbau», H. Grob.

"Prestressed Shotcrete-Steel Diaphragm Tanks", Francis X. Crowley.

"Properties of Pneumatically Placed Refractory Concretes", A. F. Livovich.

"Shotcrete Repairs of Waterfront Substructures", Paul J. Fluss and Glenn E. Gibson.

\section{résumé}

Technologie de la ugunita»

Luis Martínez Díaz, Dr. ingénieur des Ponts et Chaussées

Dans cet article l'auteur décrit les caractéristiques, les dénominations, le dosage et les utilisations, ainsi que les normes pour un parfaite exécution et mise en oeuvre des mortiers et bétons tranportés à l'aide de tuyaux et projetés pneumatiquement a grande vitesse sur une surface, qui portent en Espagne le nom générique de "gunita".

\section{summary}

\section{Gunnite technology}

Luis Martínez Díaz, Dr. civil engineer

This article describes the characteristics, applications, proportioning practice, and other features, as well as the right specifications applicable to mortars and concretes which are transported by means of rubber tubes and ces, i.e., it deals with the technology of gin sprayed concrete.

\section{zusammenfassung}

Technologie des Torkretverfahrens

Luis Martínez Díaz, Dr. Tiefbauingenieur

In diesem Artikel werden die Charakteristika, Bezeichnungen, Dosierungen und Anwendungsmöglichkeiten des Torkretverfahrens beschrieben sowie die Normen für eine korrekte Durchführung und Aufbringung von Mörtel und Beton, die bel hohen Geschwindigkeiten unter Luftdruck durch Schläuche auf eine Fläche aufeine Fläche aufgespritzt werden. 